\title{
Reducing miR485-3p ameliorates Alzheimer's disease pathology by regulation of amyloid beta and neuro-inflammation
}

Han Seok Koh

BIORCESTRA Co., Ltd

Hannah Jang

BIORCHESTRA Co., Ltd

SooKil Tae

BIORCHESTRA Co., Ltd

mi-sun Lee

BIORCHESTRA Co., Ltd

Jae-Woong Min

BIORCHESTRA Co., Ltd

Hui jin Mun

Konyang University College of Medical Science

Ji na Lee

Konyang University College of Medical Science

Hyo Jin Lee

BIORCHESTRA Co., Ltd

Dae Hoon KIM

BIORCHESTRA Co., Ltd

Hyun-Jeong Cho

Konyang University College of Medical Science

Jin-Hyeob Ryu ( $\square$ ceo@biorchestra.com )

BIORCHESTRA Co.,Ltd

Research article

Keywords: Alzheimer`s disease, miR485-3p, antisense oligonucleotide (ASO), SIRT1, CD36, 5XFAD, glial cell

Posted Date: March 29th, 2020

DOI: https://doi.org/10.21203/rs.3.rs-19583/v1 
License: (c) (i) This work is licensed under a Creative Commons Attribution 4.0 International License. Read Full License 
4 Han Seok Koh ${ }^{1}$, Hannah Jang ${ }^{1}$, SooKil Tae ${ }^{1}$, mi-sun Lee ${ }^{1}$, Jae-Woong Min ${ }^{1}$, Hui jin Mun², Ji na Lee 5 Hyo Jin Lee ${ }^{1}$, Dae Hoon $\mathrm{KIM}^{1}$, Hyun-Jeong Cho ${ }^{1,2^{*}}$,Jin-Hyeob Ryu ${ }^{1 *}$

${ }^{1}$ BIORCHESTRA Co., Ltd, Techno4-ro 17, Daejeon 34013, South Korea

Han Seok Koh, Ph.D: kohhan@biorchestra.com

Hannah Jang, MS: steruis@biorchestra.com

Sookil Tae, Ph.D Candidate: sktae@biorchestra.com

mi-sun Lee, MS: ruans00911@biorchestra.com

Jae-Woong Min, Ph.D: mjw@biorchestra.com

Hui jin Mun, MS Candidate: gmlwls5685@naver.com

Ji na Lee: 2jn55@naver.com

Hyo Jin Lee, Ph.D Candidate: hohosaraly@biorchestra.com

Dae Hoon KIM, Ph.D: daehoonkim80@biorchestra.com 
Hyun-Jeong Cho, Prof: hjcho@konyang.ac.kr

23 Jin-Hyeob Ryu, Ph.D and CEO: ceo@biorchestra.com

24

25

*To whom correspondence should be addressed;

26 E-mail: hjcho@konyang.ac.kr, ceo@biorchestra.com

27

28

29

30

31

32

33

34

35

36

37

38

39 
40 Abstract

$41 \quad$ Background

42 Alzheimer's disease (AD) is a progressive neurodegenerative disease worldwide. 43 Accumulation of amyloid- $\beta$ (A $\beta)$, neurofibrillary tangles and neuroinflammation play the 44 important neuro-pathology in patients with AD. miRNA is multifunctional and involved in physiological and pathological processes. Recently, microRNAs have been linked to neurodegenerative diseases. However, it is little known whether miRNA dysregulation

47 contributes to $\mathrm{AD}$ pathology progression such as $\mathrm{A} \beta$ processing, phagocytosis and neuroinflammation. Here, we identify miR485-3p as a novel modulator of AD pathology in 5XFAD mice.

\section{Methods}

To study the role of miR485-3p in AD, we used in control or miR485-3p antisense oligonucleotides (miR485-3p ASO) injected 5XFAD mouse model. Changes of A $\beta$ processing and clearance and inflammation were analyzed by biochemical method in vitro and in vivo.

\section{Results}

57 This study suggests that miR485-3p, a novel miRNA targeting SIRT1 may contribute to 58 pathogenesis in an AD mouse. We found SIRT1 is significantly reduced in the precentral gyrus 59 of Alzheimer patient's and in 5XFAD mice. To determine whether the inhibition of miRNA $60485-3 p$ would affect AD pathology, we studied the effect of the antisense oligo in the brain of 61 5XFAD mice through direct intracerebral ventricular injection with miR485-3p ASO. We 
62 demonstrated that miR485-3p ASO significantly reduced A $\beta$ plaque and amyloid biosynthetic

63 enzyme. Importantly, the attenuation of A $\beta$ plaques through miR485-3p ASO was mediated

64 through A $\beta$ phagocytic activity of glial cells, by which it can directly target CD36. MiR485-3p

65 ASO also decreased inflammatory responses. Collectively, these responses inhibited neuronal

66 loss caused by $\mathrm{A} \beta$ lead to improvements of cognitive impairment.

67

68

\section{Conclusion}

69

70

71

72

73

Our data provide evidence for the molecular mechanisms which underlie the miR485-3p ASO responses in an $\mathrm{AD}$ mouse model. These results suggest that attenuating miRNA 485-3p levels might represent a novel therapeutic approach in AD.

\section{Keyword}

Alzheimer`s disease, miR485-3p, antisense oligonucleotide (ASO), SIRT1, CD36, 5XFAD, glial cell 


\section{Background}

Alzheimer's disease (AD) is a progressive neurodegenerative disorder, and the most common form of dementia in the global elderly population. AD will affect more than 100 million people worldwide by 2050 [1,2]. The characteristics of AD clinically are cognitive impairment, memory loss, social and occupational dysfunction and, ultimately, death [3]. The costs of AD are estimated at more than 800 billion USD globally [4]. Over the past two decades, investigators have been trying to develop compounds and antibodies that can inhibit A $\beta$ production and aggregation, or, promote amyloid beta clearance. Unfortunately, these attempts have not achieved successful clinical benefits in large clinical trials with mild AD patients [3]. In recent years, much attention has been focused on the therapeutic modulation of inflammation and phagocytosis during AD pathology $[5,6]$.

MicroRNAs, as non-coding single stranded RNAs, are important regulators of posttranscriptional gene expression by either translation repression or mRNA destabilization [7]. MicroRNAs have been shown to function as regulators of development, growth, differentiation and neurodegenerative processes [8]. Single microRNAs are able to regulate various genes, making microRNAs a potential therapeutic target for multifactorial conditions such as brain disease. Indeed recent reports have demonstrated that miRNAs orchestrate a variety of signaling pathways involved in the pathogenesis of $\mathrm{AD}$, including $\mathrm{A} \beta$ production and clearance, neuroinflammation and neurogenesis [9].

SIRT1 is a nicotinamide adenine dinucleotide (NAD+)-dependent deacetylase that catalyzes the removal of acetyl groups from lysine residues on histone proteins, resulting in gene silencing [10]. Due to this role, SIRT1 has been shown to regulate diverse cellular processes, including cell survival, inflammation, and stress resistance. SIRT1 plays a critical role in mitigating damage caused by aging and a number of neurodegenerative diseases 
including AD. SIRT1 is involved in AD-related pathogenic mechanisms such as abnormal amyloid beta precursor protein (APP) processing, neuroinflammation, neurodegeneration, and mitochondrial dysfunction [11]. SIRT1 deacetylates A $\beta$-processing associated transcription factors including PGC1 $\alpha$, adam10, and Rock1 [12]. In addition, SIRT1 overexpression and activation protects against $\mathrm{A} \beta$ neurotoxicity through reduced microglial expression of NF-kB. [13]. Therefore, SIRT1 is now considered to be a key transcriptional regulator responsible for controlling pathways that can contribute to AD. We hypothesized that regulation of SIRT1 in the $\mathrm{AD}$ brain could be neuroprotective because of its involvement in $\mathrm{A} \beta$ processing and inflammation.

In this paper, we describe a new factor that regulates SIRT1, and which plays an important role in AD pathology. Notably, our data show that expression of SIRT1 is reduced in brains of AD patients and 11-mo-old 5XFAD AD mice. We found miR485-3p among many miRNAs is a SIRT1 regulator. Specific inhibition of miR485-3p in neurons and glial cells results in marked induction of SIRT1 expression. Upregulation of SIRT1 by miR485-3p ASO influences A $\beta$ processing through PGC-1, BACE1 and adam10 expression in neurons of 5XFAD mice. We observed that glial cells surrounding $A \beta$ plaques have a significantly greater capacity for $A \beta$ uptake in the presence of miR485-3p ASO. It also increased expression of the phagocytic receptor, CD36. Furthermore, we demonstrated that SIRT1 expression is induced by miR485$3 \mathrm{p}$ ASO and results in diminished neuroinflammation in glial cells through regulation of NF$\kappa \mathrm{B}$ expression in vivo and in vitro. These phenomena ultimately prevent neuronal damage and improved cognitive decline in AD mice. Collectively, our results suggest that miR485-3p ASOinduced SIRT1 may be an important molecular approach in AD pathology and insights may contribute to the development of new therapeutic strategies for AD. 


\section{Human tissue}

Brain precentral gyrus samples from patients with $\mathrm{AD}$ and from controls were purchased from Netherlands brain bank. Information related to these patients and controls is shown in (Additional file 1: Table S1).

Mice

B6SJLF1/J (JAX\#100012), and five familial AD mutation (5XFAD) transgenic mice (\#MMRRC\#034848) were purchased from The Jackson Laboratory (Bar Harbor, ME, USA).

\section{Next generation sequencing using mouse frontal cortex tissue}

NGS was performed in a NovaSeq 6000 system (Illumina, https://www.illumina.com/) by the 
processed using 'Raw read' for mRNA sequencing. Raw reads were aligned to GRCm38.96 (NCBI) using STAR aligner v2.7.1 for calculation of 'RSEM' expression values [14]. We performed the STAR aligner as the default option. Since the total number of reads for each sample was different, normalization was performed by TMM method. Thirteen mouse samples were processed in the same way. All data is available in the GEO (Gene Expression Omnibus, https://www.ncbi.nlm.nih.gov/geo/) as GSE142633.

\section{Public database usage, reanalysis and network analysis}

We used results from Weinberg et al. to confirm miRNAs that are highly related to cognitive impairment [15]. The 100 genes shown in Figure S1 were extracted from Table 1 of Weinberg et al. We took $\log 2$ in Weinberg et al.'s results, ordered them, and marked the target miRNAs. The "miRDB" was used to search for miRNA targeting specific genes [16]. The "Genecard" database was used to search for genes related to disease or biological symptoms [17]. The results in Figure S2a show search results from using keywords, "Inflammation", "Amyloid beta degradation" and "Alzheimer" in August 2019. We used "VennDiagram" package of R for analysis for Venn diagram. The "GeneMAINA" (version 3.5.1) package of Cytoscape (version 3.7.1) was used for protein to protein interaction analysis [18]. We used 265 common genes that included hsa-miR-485-3p target genes and Alzheimer-related genes as inputs for protein interaction analysis. Among them, 139 genes interacted without neighbor gene. In addition, 9 genes were highly associated with cerebral nervous system diseases (including AD) and at the same time, low expression was reported in the patient group or in a dementia mouse model [19-26]. Nine genes are indicated by red font in Figure S2b. 
The miR485-3p ASO (AGAGAGGAGAGCCGUGUAUGAC) were synthesized by Integrated DNA Technologies (USA). Non-targeting ASO (negative control, Cat\#AM17010) were purchased from ThermoFisher (USA). All animals were initially anesthetized with $3-5 \%$ isoflurane in oxygen and fixed on a stereotaxic frame (JeongDo). For intracerebroventricular (ICV) injection, miR485-3p ASO or non-targeting control oligonucleotides were formulated with in vivo jetPEI reagent (Polyplus). miR485-3p ASO (1.5 $\mu \mathrm{g})$ or control oligonucleotide formulated with in vivo jetPEI reagent, was injected with a 10ul Hamilton syringe (26-gauge blunt needle) at $1.5 \mathrm{ul} / \mathrm{min}$. miR $485-3 \mathrm{p} \mathrm{ASO}$ were infused in a volume of $5 \mu \mathrm{l}$ into 10 month old 5XFAD mice by intracerebroventricular (ICV). miR485-3p ASO or non-targeting control oligonucleotides were given once a week for 2 weeks. Intracerebroventricular (ICV) position was identified using the coordinates from the bregma: $\mathrm{AP}=-0.2 \mathrm{~mm}, \mathrm{~L}= \pm 1.0 \mathrm{~mm}$, ventral $(\mathrm{V})=$ $-2.5 \mathrm{~mm}$.

\section{Glial cell and cortical neuron culture and transfection}

Mouse primary mixed glial cells were cultured from the cerebral cortices of 1- to 3-day-old C57BL/6 mice. The cerebral cortex was dissected and triturated into single-cell suspensions by pipetting. Then, single-cell suspensions were plated into 6 well plates pre-coated with 0.05 $\mathrm{mg} / \mathrm{ml}$ poly-D-lysine (PDL) and cultured in DMEM medium supplemented with $25 \mathrm{mM}$ glucose, $10 \%$ (vol/vol) heat-inactivated foetal bovine serum, $2 \mathrm{mM}$ glutamine and 1,000 units/ml penicillin-streptomycin $(\mathrm{P} / \mathrm{S})$ for 2 weeks. Primary cortical neurons were cultured from embryonic day 17 mice. In brief, cortices were dissected and incubated in ice-cold HBSS (Welgene, LB003-02) solution and dissociated in accumax (sigma, Cat\#A7089) for 15 min at 
$37^{\circ} \mathrm{C}$. The cultures were rinsed twice in HBSS. Mouse neurons were resuspended in neurobasal media (Gibco, Cat\#21103049) containing 2\% B27 (Gibco, Cat\#17504), 1\% sodium pyruvate, and $1 \% \mathrm{P} / \mathrm{S}$. Cells were filtered through a 70um cell strainer (SPL, 93070), plated on culture plates and maintained at $37^{\circ} \mathrm{C}$ in a humidified $5 \% \mathrm{CO} 2$ incubator. The medium was changed every 3 days and then after 12-13 days in vitro, cells used for experiments. Primary glial cell or cortical neurons were transfected with $100 \mathrm{nM}$ miR-control, $100 \mathrm{nM}$ has-miR485-3p mimic or 100nM miR485-3p ASO using TransIT-X2® Transfection Reagent (Mirus Bio).

\section{Luciferase assays}

Human SIRT1 3'-UTR containing the target site for miR-485-3p was amplified from cDNA by PCR amplification and inserted into the psiCHECK2 vector (Promega, Cat\#C8021). HEK293T cells in a 96-well plate were co-transfected with psiCHECK2-Sirt1-3'UTR WT or psiCHECK2-Sirt1-3'UTR MT and miR-485-3p using Lipofectamine 2000 (Invitrogen, Cat\#11668-027). Cells were harvested 48hr later, and the Dual Luciferase Assay System (Promega, Cat\#E1910) was used to measure the luciferase reporter activities. Three independent experiment were performed in triplicate.

Human CD36 3'-UTR containing the target site for miR-485-3p was amplified from cDNA by PCR amplification and inserted into the pMir-Target vector (Addgene). HEK293T cells in 96well plates were co-transfected with pMir-CD36-3'UTR WT or pMir-CD36-3'UTR MT and pRL-SV40 vector (Addgene) and miR-485-3p using Lipofectamine 2000 (Invitrogen, Cat\#11668-027). Cells were harvested 24 48hr later, and the Dual Luciferase Assay System (Promega, Cat\#E1910) was used to measure the luciferase reporter activities. Three independent experiment were performed in triplicate. 
Streptavidin magnetic beads (Invitrogen, Cat\#11205D) were prepared for in vitro binding assay as follows. Beads ( $50 \mathrm{ul}$ ) were washed five times with $500 \mathrm{ul}$ of $1 \mathrm{X}$ B\&W buffer ( $5 \mathrm{mM}$ Tris$\mathrm{HCl}$, pH 7.4; 0.5 mM EDTA; $1 \mathrm{M} \mathrm{NaCl}$ ). After removing the supernatant, beads were incubated with 500 ul of $1 X$ B\&W buffer containing 100 ug of yeast tRNA (Invitrogen, Cat\# AM7119) for 2 hours at $4^{\circ} \mathrm{C}$. Beads were washed twice with $500 \mathrm{ul}$ of $1 \mathrm{X} \mathrm{B \& W}$ buffer and incubated with 200 ul of $1 \mathrm{X} \mathrm{B \& W}$ buffer containing 400 pmol of biotin-miR485-3p for 10 minutes at room temperature. The supernatant was removed and beads were washed twice with $500 \mathrm{ul}$ of 1X B\&W buffer and collected with a magnetic stand. miRNA-coated beads were incubated with $500 \mathrm{ul}$ of $1 \mathrm{X} \mathrm{B} \& \mathrm{~W}$ buffer containing $1 \mathrm{ug}$ of in vitro transcribed target mRNA overnight at $4{ }^{\circ} \mathrm{C}$. The following day, beads were washed with $1 \mathrm{ml}$ of $1 \mathrm{X} \mathrm{B} \& \mathrm{~W}$ buffer five times and then resuspended in $200 \mathrm{ul}$ of RNase-free water. Bound RNA was extracted with QiaZol Lysis reagent (Qiagen, Cat\#79306) under manufacturer's instructions. Extracted RNA was quantified by StepOnePlus Real-time PCR system (Applied Biosystems, REF: 4376592).

\section{Western blot}

238

Brain tissue, primary glial cells or cortical neuron cells were homogenized in ice-cold RIPA buffer (iNtRON Biotechnology) containing protease/phosphatase inhibitor cocktail (Cell Signaling Technology, Cat\#5872) on ice for $30 \mathrm{~min}$. The lysates were centrifuged at 13,000rpm for $15 \mathrm{~min}$ at $4{ }^{\circ} \mathrm{C}$, and supernatants were collected. The samples were separated by SDSpolyacrylamide gel electrophoresis, transferred to PVDF membranes and incubated with the following primary antibodies: rabbit anti-PGC-1 $\alpha$ (Abcam, Cat\# ab54481, 1:1000), rabbit antiAPP (Cell Signaling Technology, Cat\#2452, 1:1000), mouse anti-sAPP $\alpha$ (IBL, Cat\#11088, 1:1000), mouse anti-sAPP $\beta$ (IBL, Cat\#10321, 1:1000), rabbit anti-Adam10 (Abcam, 
246 Cat\#ab1997, 1:100), mouse anti-CTFs (Biolegend, Cat\#SIG-39152, 1:1000), rabbit anti- $\beta$ 247 amyloid (1-42) (Cell Signaling Technology, Cat\#14974, 1:1000), rabbit anti-BACE1 (Abcam, 248 Cat\# ab2077, 1:1000), mouse anti-NeuN (Millipore, \#MAB377, 1:1000), rabbit anti-cleaved 249 caspase 3 (Cell Signaling Technology, Cat\#9664, 1:1000), mouse anti-GFAP (Merck, 250 Cat\#MAB360, 1:1000), rabbit anti-IL-1ß (abcam, Cat\#9722, 1:1000), rabbit anti-NF-kB(p65)

251 (Cell Signaling Technology, Cat\#8242, 1:1000), goat anti-Iba1 (Abcam, Cat\#ab5076, 1:1000), 252 rabbit anti-SIRT1 (Abcam, Cat\#04-1557), mouse anti-TNF- $\alpha$ (Santa Cruz, Cat\#sc-52746), 253 anti-actin (Santa Cruz, Cat\#sc-47778). The results were visualized using an enhanced chemiluminescence system, and quantified by densitometric analysis (Image J software, NIH). All experiments were performed independently at least three times.

\section{Insoluble $A \beta$ extraction}

258

Brain tissue samples were homogenized with RIPA buffer containing protease/phosphatase inhibitors on ice, followed by centrifugation at $12,000 \mathrm{rpm}$ for $15 \mathrm{~min}$. The supernatants were collected. To obtain the insoluble fraction from brain tissues, the pellet of brain lysates was lysed in insoluble extraction buffer [50mM Tris-HCl (pH7.5) $+2 \%$ SDS] containing protease/phosphatase inhibitor cocktail on ice for $30 \mathrm{~min}$. The lysates were centrifuged at $4{ }^{\circ} \mathrm{C}$ for $15 \mathrm{~min}$ at 13,000 rpm. Protein was quantified using bicinchoninic acid (BCA) assay kit (Bio-Rad Laboratories, Cat\#5000116) and adjusted to the same final concentration. After denaturation, the lysates were processed for western blotting to measure insoluble $A \beta$. 
For immunohistochemistry, oligonucleotide injected 5XFAD brains were removed, postfixed and embedded in paraffin. Coronal sections $(10-\mu \mathrm{m}$ thick) through the infarct were cut using a microtome and mounted on slides. The paraffin was removed, and the sections were washed with PBS-T and blocked in $10 \%$ bovine serum albumin for $2 \mathrm{~h}$. Thereafter, the following primary antibodies were applied: Purified mouse anti- $\beta$-Amyloid, 1-16 (Biolegend, \#803001, $1 \mu \mathrm{g} / \mathrm{ml}$ ), rabbit anti- $\beta$-amyloid (1-42 (Cell Signaling Technology, \#14974s, 1:100), rabbit antiIba-1 (Wako, \#019-19741, $2 \mu \mathrm{g} / \mathrm{ml}$ ), goat anti-Iba-1 (Abcam, \#ab5076, $2 \mu \mathrm{g} / \mathrm{ml}$ ), rabbit antiCD68 (Abcam, \#ab125212, $1 \mu \mathrm{g} / \mathrm{ml}$ ), rabbit anti-GFAP (Abcam, \#ab16997, 1:100), mouse anti-GFAP (Millipore, \#MAB360, 1:500) rat anti-CD36 (Abcam, \#ab80080, 1:100), mouse anti-TNF- $\alpha$ (Santa Cruz, \#sc-52746, 1:100), rabbit anti-IL-1 $\beta$ (Abcam, \#ab9722, $1 \mu \mathrm{g} / \mathrm{ml}$ ), rabbit anti-cleaved caspase-3 (Cell Signaling Technology, \#9662S, 1:300), mouse anti-NeuN (Millipore, \#MAB377, $10 \mu \mathrm{g} / \mathrm{ml}$ ). Images were obtained using a confocal microscope (Leica DMi8). Relative band intensity was normalized relative to actin using ImageJ software (NIH).

\section{Thioflavin-S staining}

For thioflavin-S(ThS) staining, the sliced brains were stained with filtered $1 \%$ aqueous Thioflavin-S solution for $8 \mathrm{~min}$. The sections were then rinsed with $80 \%, 95 \%$ ethanol and three washes with distilled water. Afterward, brain slices were mounted and slides allowed to dry in the dark overnight. Images were taken on a Leica fluorescence microscope.

Preparation of $A \beta_{1-42}$ fibrils

$A \beta_{1-42}$ Hexafluoroisopropanal (HFIP) peptide (\#AS-64129) was obtained from AnaSpec 
291

292

fA $\beta$ synthetic human $A \beta_{1-42}, A \beta_{1-42}$. HFIP peptide was dissolved in DMSO to a stock concentration of $5 \mathrm{mM}$. Stocks were then diluted to $100 \mu \mathrm{M}$ in serum free DMEM and incubated at $37^{\circ} \mathrm{C}$ for $72 \mathrm{~h}$. Fibrillar $\mathrm{A} \beta$ (fA $\beta$ ) were confirmed by SDS-PAGE.

\section{In vitro phagocytosis assays (ELISA and immunocytochemistry)}

BV2 microglial cells $\left(2 \times 10^{5}\right)$ were plated in 6-well plates overnight. Cells were transfected using a TransIT-X2® Transfection Reagent (Mirus Bio, Cat\#MIR6000) according to the manufacturer's instructions and treated with $\mathrm{fA} \beta$ for $4 \mathrm{~h}$ at a final concentration of $1 \mu \mathrm{M}$. In some case anti-CD36 was applied to the media with $\mathrm{fA} \beta$. After $4 \mathrm{~h}$, media was collected from BV2 microglia. Levels of human $A \beta(1-42)$ in supernatant were measured by the human $A \beta 42$ ELISA kit (Invitrogen, Cat\#KHB3441), according to the manufacturer`s instructions.

In addition, glial phagocytosis was verified by fluorescence microscope. Coverslips were coated with poly-l-lysine before plating $8 \times 10^{4}$ primary glial cells per coverslip resting in wells of a 24-well plate overnight. Primary glial cells were transfected using TransIT-X2® Transfection Reagent (Mirus Bio) according to the manufacturer`s instructions and incubated in unlabeled $\mathrm{fA} \beta$ for $4 \mathrm{~h}$ at a final concentration of $1 \mu \mathrm{M}$. After $4 \mathrm{~h}$, the cells were washed with cold PBS. For A $\beta$ uptake measurement, primary glial cells were then fixed with $100 \%$ methanol for $1 \mathrm{~h}$ at $-20^{\circ} \mathrm{C}$, washed with PBS-T and incubated at $4{ }^{\circ} \mathrm{C}$ with mouse anti- $\beta$-Amyloid $1-16$,

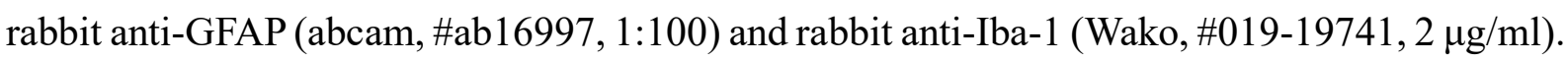

\section{FACS analysis}


312 All staining steps were performed in the dark and blocked with BD Fc Block. Primary glial cells were stained using the following antibodies: Alexa 488-conjugated anti-mouse CD36 analysed with CellQuest (BD Bioscience) and FlowJo software (Treestar) packages.

\section{Real time PCR}

Total RNA was isolated using the Isolation of small and large RNA kit (Macherey Nagel,

Dfiren). cDNA was synthesized using miScript II RT Kit (Qiagen, Hilden, Germany). For analysis the expression of miR-485-3p was performed by TaqMan miRNA analysis using TOPreal $^{\mathrm{TM}}$ qPCR 2X PreMIX (Enzynomics, Korea) on CFX connect system (Bio-Rad). The real-time PCR measurement of individual cDNAs was performed using SYBR green and Taq man probe to measure duplex DNA formation with the Bio-Rad real-time PCR system. Primers were as follows: Probe: FAM-CGAGGTCGACTTCCTAGA-NFQ. miR-485-3p forward: 5'-

CATACACGGCTCTCCTCTCTAAA-3'; Mouse primer: Actin forward: 5'TCCTGTGGCATCCATGAAAC-3', reverse: 5'-CAATGCCTGGGTACATGGTG-3'; TNF forward: 5'-CCAAGTGGAGGAGCAGCT-3', reverse: 5'-GACAAGGTACAACCCATCGG-

CAGCCTAGCAGCACGTAAAT-3'; reverse: 5'-GAATCGAGCACCAGTTACG-3'; miR16 level was used for normalization. The relative gene expression was analyzed by the $2-\Delta \Delta \mathrm{ct}$ method. 
The Y-maze consisted of three black, opaque, plastic arms $(30 \mathrm{~cm} \times 8 \mathrm{~cm} \times 15 \mathrm{~cm}) 120^{\circ}$ from each other. The 5XFAD mice were placed in the center and were allowed to explore all three arms. The number of arm entries and number of trials (a shift is $10 \mathrm{~cm}$ from the center, entries into three separate arms) were recorded to calculate the percentage of alternation. An entry was defined as all three appendages entering a Y-maze arm. Alternation behavior was defined as the number of triads divided by the number of arm entries minus 2 and multiplied by 100 . The passive avoidance chamber was divided into a white (light) and a black (dark) compartment $(41 \mathrm{~cm} \times 21 \mathrm{~cm} \times 30 \mathrm{~cm})$. The light compartment contained a $60 \mathrm{~W}$ electric lamp. The floor (of the dark) department contained a number of (2-mm) stainless steel rods spaced $5 \mathrm{~mm}$ apart. The test was done for 3 days. The first day adapts the mouse for 5 minutes in a bright zone. The second day is the training phase. The study consists of two steps. The first step places each mouse in the light zone which is then moved to the dark zone twice. One hour after the first step, each mouse is placed in the light compartment. The door separating the two compartments was opened 30 seconds later and after mice enter the dark compartment, the door was closed and an electrical foot shock $(0.3 \mathrm{~mA} / 10 \mathrm{~g})$ was delivered through the grid floor for 3 seconds. If the mouse does not go into the dark zone for more than 5 minutes, it is considered to have learned avoidance, and the training was done up to 5 times. Twenty-four hours after the training trial, mice were placed in the light chamber for testing. Latency was defined as the time it took for a mouse to enter the dark chamber after the door separating the two compartments opened. The time taken for the mouse to enter the dark zone and exit to the bright zone was defined as TDC (time spent in the dark compartment).

\section{Data analysis}

All data are presented as the mean \pm SD. NGS data were analyzed using R (version 3.5.2). 
360 Statistical significance in the values obtained for two different groups were determined using 361 unpaired $t$-test. Statistical tests were performed using GraphPad Prism 5 (GraphPad Software, 362 La Jolla, CA). Behavior tests were assessed by nonparametric statistical procedures.

363

364

365

366

367

368

369

370

371

372

373

374

375

376

377

378

379 


\section{Results}

\section{SIRT1 expression is decreased in brains of AD patients and in late stage AD mice.}

Previous studies reported that SIRT1 levels were reduced in brains of human AD patients and this reduction affected AD progression from early to late stages [28,29]. We hypothesized that increasing SIRT1 might have prophylactic effects that could alleviate AD. For this, we first examined levels of SIRT1 protein in AD patient postmortem brain (precentral gyrus) samples. We found that SIRT1 protein levels were notably reduced in AD patient brains compared to normal human brains (Fig. 1a, b and Additional file 1: Table S1). To confirm these results, we obtained brain frontal cortex samples from 6 mo-old 5XFAD mice and 11 mo-old 5XFAD mice, then analyzed the expression levels of SIRT1 using next generation sequencing (NGS). Interestingly, we observed there was no difference in SIRT1 expression between 6 mo-old 5XFAD and WT mice, while it was markedly decreased in 11-mo-old 5XFAD mice compared with WT mice (Fig 1c). SIRT1 expression was gradually reduced as the 5XFAD aged mice (Fig. 1d). Taken together, these findings suggest that SIRT1 expression is down-regulated in $\mathrm{AD}$, and imply that SIRT1 may play a role in AD pathogenesis.

\section{SIRT1 is a direct target of miR-485-3p}

Based on the above observation, we next searched for miRNA candidates that could regulate SIRT1. We first wanted to know which miRNAs were overexpressed in AD patient derived brain samples. To do this, we reanalyzed a previously published small RNA-Seq dataset [15]. We found that miR485-3p was increased in AD frontal cortex (Additional file 2: Figure S1a). Consistent with this, miR485-3p was significantly higher in AD precentral gyrus tissue than in normal tissue while miR485-5p was not significantly different between AD and normal 
403 (Additional file 2: Figure S1b). Surprisingly, across the list of SIRT1 related miRNAs, the only 404 one upregulated in AD patients was miR485-3p (Additional file 2: Figure S1c). Based on three public prediction algorithms, including targetscan, miRDB and miRbase, miR-485-3p has a binding site in the 3'UTR of SIRT1. To evaluate the prediction, we first investigated whether human miR485-3p mimic and ASO regulates miR485-3p expression in the mouse. Realtime PCR showed that the expression of miR485-3p in mouse primary cortical neurons was markedly reduced by transfection with human miR485-3p ASO (Additional file 2: Figure S1d). We next transfected miR-control, human miR485-3p or miR485-3p ASO into mouse primary cortical neurons, and measured the expression of SIRT1. SIRT1 protein was reduced in miR485-3p transfected primary cortical neurons compared to miR-control transfected neurons (Fig. 2a, b). In contrast, miR485-3p ASO transfection elevated SIRT1 expression (Fig 2a, b). Prior studies reported that SIRT1 regulated PGC-1 $\alpha$ transcription in C2C12 myoblasts [30] and miR485-3p directly regulated PGC-1 $\alpha$ expression through 3'UTR binding [31]. We confirmed that SIRT1 and PGC-1 $\alpha$ were correlated using protein-protein network analysis of miR485-3p target genes (Additional file 3: Figure S2a, b). We also demonstrated that PGC-1 $\alpha$ protein was regulated by transfection of miR485-3p and miR485-3p ASO in primary cortical neurons (Fig. 2a, b). Next, we examined the miR-485-3p targeting site in the $3^{`}$-UTR of SIRT1. To confirm the target site for miR-485-3p, we constructed reporter plasmids of the SIRT1 3'-UTR containing either wild-type or mutated sequence of the potential miR485-3p site (Fig. 2c). We transfected HEK293T cells with either wild-type or mutant sequence luciferase reporter, and measured promoter activity. As expected, wild type promoter activity was significantly reduced but the mutant form was not different in miR485-3p transfected cells (Fig. 2d). In addition, we identified the physical binding of miR485-3p to the 3' UTR of SIRT1 by in vitro binding assay. Streptavidin-miR483-3p-coated magnetic beads were incubated with in vitro transcribed wild type 3' UTR and mutant 3' UTR of SIRT1 respectively. Binding RNA was eluted and quantified 
by realtime PCR. Relative binding was calculated using the formula: Relative Binding =

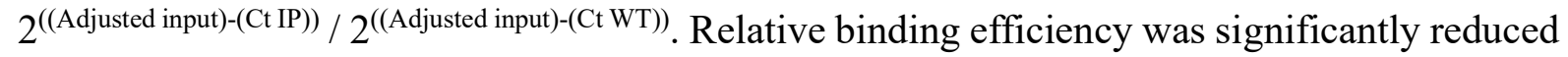
in 3' UTR containing mutant seed sequences compared to WT seed sequences (Fig. 2e). Collectively, these results indicate that miR485-3p directly targeted the 3 '-UTR of SIRT1 and negatively regulated SIRT1 expression.

MiR485-3p ASO significantly reduces A $\beta$ plaques by altering amyloid beta processing in 5XFAD.

Since we found SIRT1 is up-regulated in neurons exposed to miR485-3p ASO, we explored whether human miR485-3p ASO exerts beneficial effects on the pathology of AD as judged by amyloid plaque formation and insoluble $\mathrm{A} \beta$ levels in 10 mo-old 5XFAD. 5XFAD transgenic mice show amyloid plaque deposition starting at 2 months [32]. A $\beta$ in brain, aggregates into insoluble clusters or plaques as AD progresses [33,34]. To investigate, miR485-3p ASO formulated with in vivo jetPEI reagent was injected in the right lateral ventricle by stereotaxic injection, and the injections were repeated at day 7 (Fig. 3a). The efficacy of miR485-3p ASO in brain was confirmed using qRT-PCR and its functional outcomes assessed by miR485-3p expression (Additional file 4: Figure S3). We next investigated the effect of a miR485-3p ASO in 10-mo-old 5XFAD using 6E10 staining and thioflavin S. The number of amyloid plaques was markedly decreased in 5XFAD that were given $1.5 \mu \mathrm{g}$ intracerebroventricular injections, compared to control miR-injected mice, suggesting that miR485-3p ASO may have ameliorated the amyloid burden (Fig. 3b, c, Additional file 5: Figure S4). To further investigate 449 the effect of the miR485-3p ASO on A $\beta$ production, we examined the level of insoluble A $\beta$ 1- 
451 ADAM(A disintegrin and metalloprotease) 10, and $\beta$-secretase BACE1, in frontal cortex of

452

453

454

455

456

457

458

459

460

461

462

463

464

465

466

467

468

469

470

471

472

473

5XFAD mice. As shown in fig. 3d-e, insoluble A $\beta$ 1-42 production significantly decreased in tissue from the frontal cortex of miR485-3p ASO -injected 5XFAD mice compared to control -injected 5XFAD. However, miR485-3p ASO did not significantly affect total APP levels (Fig 3f, g). Furthermore, the brain levels of $\beta$-CTFs and sAPP $\beta$, the main products of BACE were markedly reduced in 5XFAD mice that received miR485-3p ASO (Fig 3f, g). In complete agreement, miR485-3p ASO injection in the brain of 5XFAD mice also significantly decreased BACE1 protein levels compared with control mice (Fig 3f, g). Interestingly, miR485-3p ASO -injected 5XFAD mice markedly increased Adam10 protein and sAPP $\alpha$ protein expression (Fig 3f, g). In addition, administration of miR485-3p ASO significantly reduced the levels of SIRT1 and PGC-1 $\alpha$ protein in the same situation. Together, these results indicate that the miR485-3p ASO triggers a strong reduction in both $\mathrm{A} \beta$ production and plaque formation in vivo.

\section{Treatment with the miR485-3p ASO enhances A $\beta$ phagocytosis by up-regulation of CD36.}

Alzheimer`s disease is caused by imbalances between $A \beta$ production and clearance [35]. Previous studies have shown that glial cells mediate clearance and phagocytosis of aggregated $\mathrm{A} \beta$ in $\mathrm{AD}$ brain, where they contribute to the alleviation of $\mathrm{AD}[36]$. To explore the role of glial cells further, we first performed immunohistochemistry analysis using Iba1 and 6E10 antibodies to colocalize glial cells and $\mathrm{A} \beta$ plaque. Immunohistochemistry showed that the expression of A $\beta$ in glial cells was considerably elevated in miR485-3p ASO -treated 5XFAD mice (Fig. 4a, Additional file 6: Figure S5a). CD68, a transmembrane glycoprotein of the lysosome/endosome-associated membrane glycoprotein family, acts as a scavenger receptor for debris clearance $[37,38]$.To further access $A \beta$ engulfment and clearance by glial cell, we 
quantified CD68 positive microglial phagosomes and internalized $\mathrm{A} \beta$ using CD68, 6E10 and

Ibal coimmunostaining. The clustering of Iba1+ microglia surrounding amyloid plaques exhibited a diffuse CD68 distribution in miR485-3p ASO treated 5XFAD compared with controls (Fig. 4b). To further assess the phagocytic effect of miR485-3p ASO in glia, we prepared $\mathrm{A} \beta$ aggregates by incubating $\mathrm{A} \beta$ monomers $(100 \mu \mathrm{M})$ at $37^{\circ} \mathrm{C}$ overnight then diluting the peptide stock with cell culture medium (Additional file 6: Figure S5b). BV2 microglia cell were transfected with miR485-3p ASO, and co-treated with $1 \mu \mathrm{M}$ fibrillar A $\beta$ (fA $\beta$ ) for $4 \mathrm{~h}$. A $\beta$ levels in conditioned media were gradually reduced in miR485-3p ASO transfected cells compare to control transfected cells (Fig. 4c). Consistent with the above results, miR485-3p ASO dose dependently increased the capacity for A $\beta$ uptake by BV2 microglial cell and primary glial cells (Fig. 4d, Additional file 6: Figure S5c, d). These results indicate that miR485-3p ASO enhances A $\beta$ phagocytosis in glial cell.

Previous studies have shown that the CD36/SR-BII contributes to $\mathrm{A} \beta$ phagocytosis in glia [39-41]. Furthermore, we found that miR-485-3p has a binding site in the 3 'UTR of CD36 by public prediction algorithms. We hypothesized that a miR485-3p ASO-dependent increase in CD36 expression could influence A $\beta$ phagocytosis. Accordingly, we examined the expression of CD36 in 5XFAD mice. Western blot analyses revealed that protein expression of CD36 was higher in miR485-3p ASO injected 5XFAD (Fig. 4e). In addition, CD36 expression was meaningfully higher in Iba-1-positive microglial cells using immunohistochemistry (Additional file 6: Figure S5e). Based on the above observations, we next examined whether CD36 expression in mouse primary glial cells could be altered by miR485-3p or miR485-3p ASO transfection. As shown in Fig. 4f, CD36 expression was markedly decreased in miR485$3 p$ transfected primary glial cell compared to miR-controls. In contrast, miR485-3p ASO transfection elevated CD36 expression. 
We examined miR-485-3p targeting within the 3 '-UTR of CD36 by constructing reporter plasmids containing either wild-type or mutant forms of the potential miR485-3p target site. We transfected HEK293T cells with luciferase reporter plasmids, and measured promoter activity. Wild type promoter activity was significantly reduced but the mutant form was not different in miR485-3p transfected cells (Fig. 4g). In addition, we identified a direct interaction between miR485-3p and the 3' UTR of CD36 by in vitro binding assay. Relative binding efficiency was significantly reduced in 3' UTR-containing mutant seed sequences (Fig. 4h). To more specifically assess the influence of glial CD36 on A $\beta$ phagocytosis, we examined whether a CD36 inhibitory antibody would influence glial phagocytosis. We transfected miR485-3p ASO or control into BV2 microglia cells, co-treated these cells with CD36 blocking antibody or control IgG, and then incubated with $1 \mu \mathrm{M}$ fA $\beta$ for $4 \mathrm{~h}$. A $\beta$ phagocytosis was determined by ELISA in conditioned media. A $\beta$ levels were considerably decreased in miR485-3p ASO transfected cells compared to control transfected cells, but this effect was significantly abrogated in cells treated with CD36 blocking antibody (Fig. 4i). These results clearly support the conclusion that CD36 expression is regulated in a miR485-3p dependent manner and affects A $\beta$ phagocytosis.

\section{MiR485-3p inhibitor decreases neuroinflammation in AD-like pathology.}

Studies have shown that inflammation is up-regulated in the brains of AD patients and transgenic mice with $\mathrm{AD}$-like pathology and inflammatory mediators are secreted by fA $\beta$ stimulated-glia, where they contribute to neuronal loss and cognitive decline $[42,43]$. Overexpression of SIRT1 suppressed A $\beta$ induced neuronal damage by inhibition of inflammation in glial cells [44], thereby we hypothesized that miR485-3p ASO-dependent increases of SIRT1 in A $\beta$ stimulated glial cells would influence proinflammatory cytokines 
levels. Primary glial cells transfected with miR485-3p ASO were treated with 1uM fA $\beta$. Three hours later, SIRT1 protein levels were examined. SIRT1 expression was markedly decreased in $\mathrm{fA} \beta$ treated primary glial cells, but this reduction was significantly recovered in miR485-3p ASO transfected cells (Fig. 5a, b). SIRT1 is well known to reduce inflammation by regulation

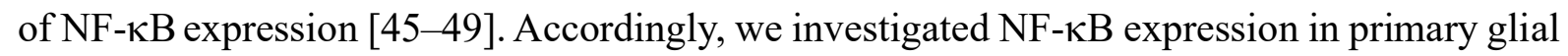
cells. The cells were transfected with miR485-3p ASO, and incubated under $1 \mu \mathrm{M}$ fA $\beta$ for $6 \mathrm{~h}$. As shown in Fig. 5a and 5b, NF- $\kappa$ B was considerably increased in control transfected cells incubated with $1 \mu \mathrm{M}$ fA $\beta$, but these enhancements were markedly reduced in cells transfected with miR485-3p ASO. To explore the anti-inflammation effects of miR485-3p ASO-induced SIRT1 expression, we measured expression levels of TNF- $\alpha$ and IL-1 $\beta$ by realtime PCR and western blot. Transfection with miR485-3p ASO significantly attenuated in fA $\beta$ stimulated TNF- $\alpha$ and IL-1 $\beta$ compare to control transfected glial cells (Fig 5a, b, Additional file 7: Figure S6a). To further assess the role of miR485-3p ASO on inflammation in 5XFAD mice, we first examined changes in Iba-1(an activated microglial marker) and GFAP (an activated astrocyte marker). Microglia expressing high levels of Iba-1 and astrocytes expressing high levels of 5XFAD mice. Importantly, the expression of the pro-inflammatory cytokines, TNF- $\alpha$ and IL$1 \beta$ were lower in the miR485-3p ASO injected mice (Fig. 5c, d). We next investigated the effect of the miR485-3p ASO on anti-inflammation responses using immunohistochemistry. Immunohistochemistry showed that TNF- $\alpha$ and IL- $1 \beta$ in glial cells was markedly attenuated in miR485-3p ASO injected 5XFAD (Fig. 5e, f, Additional file 7: Figure S6c, d). These findings strongly suggest that knocking down miR485-3p affects the activation of glial cells and reduces proinflammatory cytokine production via regulation of SIRT1/NF-кB signaling. 

studies report that synaptic and neuronal loss in 5XFAD is correlated with A $\beta$ accumulation and neuroinflammation [32,50,51]. Given our observation that SIRT1 and CD36 expression through miR485-3p ASO controls A $\beta$ processing, phagocytosis and inflammation in 5XFAD mice, we investigated the effect of the antisense inhibitor on neuronal cell death by assessing NeuN (a neuronal cell marker) and cleaved caspase-3. Western blot revealed that the expression of NeuN was increased in the miR485-3p ASO treated 5XFAD cortical region, whereas protein expression of cleaved caspase-3 was reduced. However this was not seen in hippocampus under the same conditions (Fig 6a, b). As well, immunohistochemistry showed the expression of cleaved caspase-3 in neuronal cells was markedly elevated in control treated 5XFAD, whereas this elevation was dramatically attenuated in miR485-3p ASO treated 5XFAD (Fig 6c, d). We next investigated the effect of the miR485-3p ASO on post-synapse by assessing the expression of PSD-95. As shown in Fig. 6e, f, protein levels of PSD-95 were considerably increased in the frontal cortex of miR485-3p ASO treated 5XFAD. To determine whether the increased postsynapse and reduced neuronal loss are correlated with improvement in cognitive functions, we measured cognitive function in control or miR485-3p ASO treated 5XFAD using Y-maze and passive avoidance task (PAT), which are widely accepted as behavior paradigms for evaluating spatial working memory. Two days after the last injection, we found that the spontaneous alternation percentage was significantly increased in miR485-3p ASO mice. The total number of arm entries did not differ significantly between control and miR485-3p ASO treated 5XFAD, indicating that levels of general motor and exploratory activity in the $\mathrm{Y}$-maze were not changed 568 (Fig. 6g). In addition, we examined associative memory in the passive avoidance task, based on the association formed between an electrical foot shock and a spontaneously preferred 
570

571

572

573

574 be intimately involved in neurological pathology, neuroinflammation and cognitive

575 improvement in 5XFAD mice

576

577

578

579

580

581

582

583

584

585

586

587

588

589 
Recent intensive research efforts have focused on developing therapeutic strategies for reducing $\mathrm{A} \beta$ production as a means of fighting $\mathrm{AD}$. Many candidates aimed specifically at $\mathrm{A} \beta$ processing have been investigated in attempts to try to reduce $A \beta$ levels in animal models or in patients with AD, but none have shown significant clinical benefit to date [52]. However, failures of clinical trials do not mean that the $A \beta$ hypothesis is wrong. Instead, an alternative option for $\mathrm{AD}$ therapeutics means that greater understanding of the highly complex environment of $\mathrm{AD}$ should be considered. Experimental and clinical findings indicate that $\mathrm{A} \beta$ clearance and neuroinflammation play a crucial role in the pathogenesis of AD. In addition, strategies aimed at promoting phagocytosis or limiting inflammation have been shown to have therapeutic potential in genetic AD mouse models. Thus, researchers have focused recently on triggering $A \beta$ clearance, or anti-inflammatory agents that target glia for the treatment of $A D$ [53]. In this study, we have investigated a molecular player that appears capable of performing an essential role in influencing the interdependent associations between inflammatory response, phagocytosis and $\mathrm{AD}$ pathology.

To find molecular candidates that might help to reduce AD progression, we first examined the expression pattern of SIRT1 in AD postmortem tissue and in an AD mouse model. Our experiments revealed that SIRT1 protein expression is reduced in AD precentral gyrus. NGS data showed that SIRT1 gene transcription is also decreased during AD progression in 5XFAD mice. Accumulating evidence has shown that SIRT1 plays a very important role in the progression of Alzheimer's disease. SIRT1 relies on its deacetylase activity to promote autophagy by upregulating the number of lysosomes, which in turn promotes intracellular A $\beta$ degradation [44]. SIRT1 also affects expression of pro-inflammatory cytokines by regulation of NF- $\kappa \mathrm{B}$ expression in AD [19]. Therefore, much effort has gone into looking for compounds 
or reagents that target SIRT1 to prevent AD progression.

Previous investigations have reported that alterations in miRNA expression correlated with $\mathrm{AD}$ pathological changes, including plaque accumulation and inflammation [54]. 617 Accordingly, miRNAs have received attention as potential therapeutic targets because of their role in regulating endogenous gene expression [55]. miRNA therapies fall into two categories, miRNA mimics or antagomirs. These miRNAs either directly regulate the expression of target proteins or indirectly regulate gene-related proteins contributing to $\mathrm{AD}$ pathogenesis. Therefore, manipulation of specific protein levels involved in $\mathrm{AD}$ pathogenesis can be a protective therapeutic strategy. We reanalyzed data from Weinberg et al. (2015) and found that the expression of 485-3p was increased in the cortex of AD patients [15]. Consistent with this in silico finding, we confirmed that the expression of miR485-3p was increased in AD patient postmortem tissue using realtime PCR. Interestingly, only miRNA485-3p emerged as a candidate after we had combined miRNA profiles that specifically regulate SIRT1 and overall increased miRNAs in $\mathrm{AD}$ patients.

The above results raised the possibility that miR485-3p might play important roles in AD pathology through the regulation of SIRT1. Our data identified that miR485-3p binds to the 3'UTR region of SIRT1 and regulated its protein expression in vitro. Moreover, frontal cortex obtained from miR485-3p-inhibitor injected 10-month old 5XFAD mice showed a reduced amyloid burden as well as lower APP processing enzymes. In contrast, SIRT1 expression increased in miR485-3p-inhibitor injected 5XFAD. These findings suggest that SIRT1 acts as a downstream mediator of miR485-3p that may influence the production of $A \beta$. accumulations and remove $\mathrm{A} \beta$ through phagocytosis [36]. However, $\mathrm{A} \beta$ phagocytosis becomes reduced with age, resulting in impaired $\mathrm{A} \beta$ clearance during $\mathrm{AD}$ progression [56]. In particular, 
638 it has been reported that the impairment of $\mathrm{A} \beta$ clearance is a common late-onset form of $\mathrm{AD}$ 639 [56]. Imbalance between $A \beta$ production and removal eventually lead to the accumulation of $640 \mathrm{~A} \beta$ and damage to neurons. Here, we show that treatment with miR485-3p ASO increases glial 641 recruitment around $\mathrm{A} \beta$ plaques and enhanced glial $\mathrm{A} \beta$ uptake in vitro and in vivo. Previous 642 reports have shown that CD36 is closely involved in phagocytosis of fA $\beta$ [39]. Together, Šerý et al reported that CD36 polymorphism related to AD develop [57]. We found that miR485-3p

644 ASO was able to promote A $\beta$ phagocytosis by increasing the expression of CD36 receptors. 645 These findings suggest that miR485-3p ASO induced upregulation of CD36 expression in glial cells thereby enhancing $A \beta$ phagocytosis and clearance.

On exposure to $A \beta$, glial cells induce the expression of proinflammatory cytokines, which cause neuronal and synaptic loss [53,58]. SIRT1 has been suggested to play a role in suppressing inflammation by regulation of NF- $\mathrm{KB}$ expression (Li et al, 2018). We therefore asked whether miR485-3p ASO could influence the expression of pro-inflammatory cytokines. We observed that the antisense oligonucleotide significantly diminished the expression of TNF-

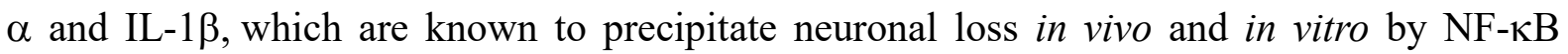
repression. We also, demonstrated that the level of PSD-95 which is related to learning and memory processes, increases considerably in miR485-3p ASO treated 5XFAD mice. These results eventually lead to improvement of memory deficits. 


\section{Conclusions}

662

663

664

665

666

667

668

669

670

671

672

673

674

675

676

677

678

679

680

678

In summary, we here present a novel function for miR485-3p as a molecular player that regulates $\mathrm{A} \beta$ accumulation and inflammation in $\mathrm{AD}$. We show that miR485-3p ASO, when used on glial cells and neurons increases the expression of SIRT1 and CD36 in AD. Increasing expression of these molecules significantly induced $\mathrm{A} \beta$ processing and phagocytosis, resulting in improvements in memory deficits in 5XFAD mice (Fig. 7). Accordingly, miR485-3p ASO may contribute to the future development of efficient therapeutic approaches against AD.

8

9

670

1

72

673

67

675

676

677

79


681 Abbreviation

682 AD: Alzheimer`s disease

683 ASO: Antisense oligonucleotide

684 fA $\beta$ : fibrillar Amyloid beta

685 SIRT1: NAD-dependent protein deacetylase sirtuin-1

686 PGC-1: Peroxisome proliferator-activated receptor-gamma coactivator 1alpha

687 APP: Amyloid beta precursor protein

688 SAPP $\alpha$ : soluble alpha-amyloid precursor protein

689 SAPP $\beta$ : soluble beta-amyloid precursor protein

$690 \quad \beta$-CTF: C-terminal fragment $\beta$

691 BACE-1: Beta secretase 1

692 Adam10: A Disintegrin and metalloproteinase domain-containing protein 10

693 Iba-1: Ionized calcium binding adaptor molecule 1

694 GFAP: Glial fibrillary acidic protein

695 NF-kB: Nuclear Factor Kappa B

696 TNF- $\alpha$ : Tumor necrosis factor alpha

697 IL-1 $\beta$ : Interleukin 1 beta

698 PSD-95: postsynaptic density protein 95

699 NeuN: Neuronal Nuclei 
701 Animal care procedures were approved by Konyang University Committee (Permit number: P-18-18-A-01).

703

704 Consent for publication

705 N/A

706

707

Availability of data and materials

708

The data generated during this study is available upon request.

709

710

\section{Competing interest}

711 The authors declare that they have no conflict of interest

712

713 Funding

714 This work was supported by the Bio \& Medical Technology Development Program of the

715 National Research Foundation (NRF) funded by the Korean government (MSIT) (No.

716 2017M3A9G2094069).

717

718 Author`s Contributions

719 HSK, JHR and HJC designed the experiments. HSK and JHR performed the data analysis and 
wrote the manuscript. HSK, HNJ and MSL performed experiments. SKT performed in vitro

721 binding assay. HJL performed primary glial cell and cortical neuron culture. HSK performed

722 the ICV injections. JWM performed bioinformatics analysis, JAL and HJM performed animal

723 behavior test. All authors read and approved the final manuscript.

724

725 Acknowledgements

726 We thank M.H Kim (BIORCHESTRA, Korea) and J.H Noh (biorchestra, Korea) for assistance

727 in performing real tine PCR and luciferase assays. We also thank all members of biorchestra 728 company.

729

730 Author's information

731

BIORCHESTRA Co., Ltd, Techno4-ro 17, Daejeon 34013, South Korea

732

Han Seok Koh, Hannah Jang, SooKil Tae, mi-sun Lee, Jae-Woong Min, Hyun-Jeong Cho \& Jin-Hyeob

733

Ryu

734

Department of Biomedical Laboratory Science, College of Medical Science, Konyang University,

735

Daejeon, South Korea.

736 Hui jin Mun, Ji na Lee \& Hyun-Jeong Cho

737

738 Corresponding Author

739 Correspondence to Jin-Hyeob Ryu \& Hyun-Jeong Cho 


\section{Reference}

742

1. Gaugler J, James B, Johnson T, Scholz K, Weuve J. 2016 Alzheimer's disease facts and figures. Alzheimer's Dement. 2016; doi:10.1016/j.jalz.2016.03.001.

2. Pan R-Y, Ma J, Kong X-X, Wang X-F, Li S-S, Qi X-L, et al. Sodium rutin ameliorates Alzheimer's disease-like pathology by enhancing microglial amyloid- $\beta$ clearance. Sci Adv. 2019; 5: aau6328.

3. Panza F, Lozupone M, Logroscino G, Imbimbo BP. A critical appraisal of amyloid- $\beta$ targeting therapies for Alzheimer disease. Nat. Rev. Neurol. 2019; 15: 73-88.

4. Alzheimer's Disease International (ADI ), Wimo A, Prince M, International AD. World Alzheimer Report 2015, The Global Impact of Dementia. Alzheimer's Dis Int (ADI ). 2015; doi:10.1111/j.0963-7214.2004.00293.x.

5. Nizami S, Hall-Roberts H, Warrier S, Cowley SA, Di Daniel E. Microglial inflammation and phagocytosis in Alzheimer's disease: Potential therapeutic targets. Br. J. Pharmacol. 2019; 176: 3515-32.

6. Kinney JW, Bemiller SM, Murtishaw AS, Leisgang AM, Salazar AM, Lamb BT. Inflammation as a central mechanism in Alzheimer's disease. Alzheimer's Dement. Transl. Res. Clin. Interv. 2018; 6: 575-90.

7. Oliveto S, Mancino M, Manfrini N, Biffo S. Role of microRNAs in translation regulation and cancer. World J Biol Chem. 2017; 8: 45-56.

8. Hammond SM. An overview of microRNAs. Adv. Drug Deliv. Rev. 2015; 29: 3-14.

9. Shaik MM, Tamargo IA, Abubakar MB, Kamal MA, Greig NH, Gan SH. The role of microRNAs in Alzheimer's disease and their therapeutic potentials. Genes (Basel). 2018; 9: pii: E174.

10. Kim D, Nguyen MD, Dobbin MM, Fischer A, Sananbenesi F, Rodgers JT, et al. SIRT1 deacetylase protects against neurodegeneration in models for Alzheimer's disease and amyotrophic lateral sclerosis. EMBO J. 2007; 26: 3169-79.

11. Cacabelos R, Carril JC, Cacabelos N, Kazantsev AG, Vostrov A V., Corzo L, et al. Sirtuins in alzheimer's disease: SIRT2-related genophenotypes and implications for 
pharmacoepigenetics. Int J Mol Sci. 2019; 20: pii: E1249.

12. Herskovits AZ, Guarente L. SIRT1 in Neurodevelopment and Brain Senescence. Neuron. $2014 ; 81,471-83$.

13. Chen J, Zhou Y, Mueller-Steiner S, Chen LF, Kwon H, Yi S, et al. SIRT1 protects against microglia-dependent amyloid- $\beta$ toxicity through inhibiting NF- $\kappa$ B signaling. J Biol Chem. 2005; 280: 40364-74.

14. Dobin A, Davis CA, Schlesinger F, Drenkow J, Zaleski C, Jha S, et al. STAR: Ultrafast universal RNA-seq aligner. Bioinformatics. 2013; 29: 15-21.

15. Weinberg RB, Mufson EJ, Counts SE. Evidence for a neuroprotective microRNA pathway in amnestic mild cognitive impairment. Front Neurosci. 2015; 9: 43.

16. Wong N, Wang X. miRDB: An online resource for microRNA target prediction and functional annotations. Nucleic Acids Res. 2015; 43: D146-52.

17. Rebhan M, Chalifa-Caspi V, Prilusky J, Lancet D. GeneCards: A novel functional genomics compendium with automated data mining and query reformulation support. Bioinformatics. 1998; 14: 656-64.

18. Franz M, Rodriguez H, Lopes C, Zuberi K, Montojo J, Bader GD, et al. GeneMANIA update 2018. Nucleic Acids Res. 2018; 46: W60-W64.

19. Quadros Gomes BA, Bastos Silva JP, Rodrigues Romeiro CF, dos Santos SM, Rodrigues CA, Gonçalves PR, et al. Neuroprotective mechanisms of resveratrol in Alzheimer's disease: Role of SIRT1. Oxid. Med. Cell. Longev. 2018; 2018:8152373.

20. Sindi IA, Tannenberg RK, Dodd PR. A role for the neurexin-neuroligin complex in Alzheimer's disease. Neurobiol. Aging. 2014; 35: 746-56.

21. Shen L, Kim S, Risacher SL, Nho K, Swaminathan S, West JD, et al. Whole genome association study of brain-wide imaging phenotypes for identifying quantitative trait loci in MCI and AD: A study of the ADNI cohort. Neuroimage. 2010; 53: 1051-63.

22. Ammendrup-Johnsen I, Naito Y, Craig AM, Takahashi H. Neurotrophin-3 enhances the synaptic organizing function of trkc-protein tyrosine phosphatase $\sigma$ in rat hippocampal neurons. J Neurosci. 2015; 35: 12425-31. 
23. Kim YJ, Yoo JY, Kim OS, Kim H byeol, Ryu J, Kim HS, et al. Neuregulin 1 regulates amyloid precursor protein cell surface expression and non-amyloidogenic processing. $\mathrm{J}$ Pharmacol Sci. 2018; 137, 146-53.

24. Manczak M, Kandimalla R, Fry D, Sesaki H, Hemachandra Reddy P. Protective effects of reduced dynamin-related protein 1 against amyloid beta-induced mitochondrial dysfunction and synaptic damage in Alzheimer's disease. Hum Mol Genet. 2016; 25: 5148-66.

25. Jacob CP, Koutsilieri E, Bartl J, Neuen-Jacob E, Arzberger T, Zander N, et al. Alterations in expression of glutamatergic transporters and receptors in sporadic Alzheimer's disease. J Alzheimer's Dis. 2007; 11: 97-116.

26. Hadley D, Wu ZL, Kao C, Kini A, Mohamed-Hadley A, Thomas K, et al. The impact of the metabotropic glutamate receptor and other gene family interaction networks on autism. Nat Commun. 2014; 5: 4074.

27. Coraci IS, Husemann J, Berman JW, Hulette C, Dufour JH, Campanella GK, et al. CD36, a class B scavenger receptor, is expressed on microglia in Alzheimer's disease brains and can mediate production of reactive oxygen species in response to $\beta$-amyloid fibrils. Am J Pathol. 2002; 160: 101-12.

28. Julien C, Tremblay C, Émond V, Lebbadi M, Salem N, Bennett DA, et al. Sirtuin 1 reduction parallels the accumulation of tau in alzheimer disease. J Neuropathol Exp Neurol. 2009; 68: 48.

29. Lutz MI, Milenkovic I, Regelsberger G, Kovacs GG. Distinct patterns of sirtuin expression during progression of Alzheimer's disease. NeuroMolecular Med. 2014; 16: 40514.

30. Amat R, Planavila A, Chen SL, Iglesias R, Giralt M, Villarroya F. SIRT1 controls the transcription of the peroxisome proliferator-activated receptor- $\gamma$ co-activator- $1 \alpha(\mathrm{PGC}-1 \alpha)$ gene in skeletal muscle through the PGC-1 $\alpha$ autoregulatory loop and interaction with MyoD. J Biol Chem. 2009; 284: 21872-80.

31. Lou C, Xiao M, Cheng S, Lu X, Jia S, Ren Y, et al. MiR-485-3p and mir-485-5p suppress breast cancer cell metastasis by inhibiting PGC-1 $\alpha$ expression. Cell Death Dis. 2016; 7: e2159. 
32. Eimer WA, Vassar R. Neuron loss in the 5XFAD mouse model of Alzheimer's disease correlates with intraneuronal A $\beta 42$ accumulation and Caspase- 3 activation. Mol Neurodegener. 2013; 8: 2.

33. Näslund J, Schierhorn A, Hellman U, Lannfelt L, Roses AD, Tjernberg LO, et al. Relative abundance of Alzheimer $A \beta$ amyloid peptide variants in Alzheimer disease and normal aging. Proc Natl Acad Sci U S A. 1994; 91: 8378-82.

34. Shinkai Y, Yoshimura M, Morishima-Kawashima M, Ito Y, Shimada H, Yanagisawa K, et al. Amyloid $\beta$-protein deposition in the leptomeninges and cerebral cortex. Ann Neurol. 1997; 42: 899-908.

35. Mawuenyega KG, Sigurdson W, Ovod V, Munsell L, Kasten T, Morris JC, et al. Decreased clearance of CNS $\beta$-amyloid in Alzheimer's disease. Science (80- ). 2010; 330: 1774.

36. Ries M, Sastre M. Mechanisms of A $\beta$ clearance and degradation by glial cells. Front. Aging Neurosci. 2016; 8: 160.

37. Yamada Y, Doi T, Hamakubo T, Kodama T. Scavenger receptor family proteins: Roles for atherosclerosis, host defence and disorders of the central nervous system. Cell. Mol. Life Sci. 1998; 54: 628-40.

38. De Villiers WJS, Smart EJ. Macrophage scavenger receptors and foam cell formation. J Leukoc Biol. 1999; 66: 740-6.

39. El Khoury JB, Moore KJ, Means TK, Leung J, Terada K, Toft M, et al. CD36 mediates the innate host response to $\beta$-amyloid. J Exp Med. 2003; 197: 1657-66.

40. Yamanaka M, Ishikawa T, Griep A, Axt D, Kummer MP, Heneka MT. PPAR /RXRAinduced and CD36-mediated microglial amyloid- $\beta$ phagocytosis results in cognitive improvement in amyloid precursor protein/presenilin 1 mice. J Neurosci. 2012; 32: 17321-31.

41. Jones RS, Minogue AM, Connor TJ, Lynch MA. Amyloid- $\beta$-induced astrocytic phagocytosis is mediated by CD36, CD47 and RAGE. J Neuroimmune Pharmacol. 2013; 8: 301-11.

42. Cunningham C, Wilcockson DC, Campion S, Lunnon K, Perry VH. Central and systemic endotoxin challenges exacerbate the local inflammatory response and increase neuronal death 
during chronic neurodegeneration. J Neurosci. 2005; 25: 9275-84.

43. Holmes C, El-Ok1 M, Williams AL, Cunningham C, Wilcockson D, Perry VH. Systemic infection, interleukin $1 \beta$, and cognitive decline in Alzheimer's disease. J Neurol Neurosurg Psychiatry. 2003; 74: 788-9

44. Li MZ, Zheng LJ, Shen J, Li XY, Zhang Q, Bai X, et al. SIRT1 facilitates amyloid beta peptide degradation by upregulating lysosome number in primary astrocytes. Neural Regen Res. 2018; 13: 2005-13.

45. Li G, Xia Z, Liu Y, Meng F, Wu X, Fang Y, et al. Sirt1 inhibits rheumatoid arthritis fibroblast-like synoviocyte aggressiveness and inflammatory response via suppressing $\mathrm{nf}-\kappa \mathrm{b}$ pathway. Biosci Rep. 2018; 38: pii: BSR20180541.

46. Yeung F, Hoberg JE, Ramsey CS, Keller MD, Jones DR, Frye RA, et al. Modulation of NF-кB-dependent transcription and cell survival by the SIRT1 deacetylase. EMBO J. 2004; 23: $2369-80$.

47. Chen J, Zhou Y, Mueller-Steiner S, Chen LF, Kwon H, Yi S, et al. SIRT1 protects against microglia-dependent amyloid- $\beta$ toxicity through inhibiting NF- $\kappa B$ signaling. J Biol Chem. 2005; 280: 40364-74.

48. Rajendrasozhan S, Yang SR, Kinnula VL, Rahman I. SIRT1, an antiinflammatory and antiaging protein, is decreased in lungs of patients with chronic obstructive pulmonary disease. Am J Respir Crit Care Med. 2008; 177: 861-70.

49. Schug TT, Xu Q, Gao H, Peres-da-Silva A, Draper DW, Fessler MB, et al. Myeloid Deletion of SIRT1 Induces Inflammatory Signaling in Response to Environmental Stress. Mol Cell Biol. 2010; 30: 4712-21.

50. Spangenberg EE, Lee RJ, Najafi AR, Rice RA, Elmore MRP, Blurton-Jones M, et al. Eliminating microglia in Alzheimer's mice prevents neuronal loss without modulating amyloid- $\beta$ pathology. Brain. 2016; 139: 1265-81.

51. Shao CY, Mirra SS, Sait HBR, Sacktor TC, Sigurdsson EM. Postsynaptic degeneration as revealed by PSD-95 reduction occurs after advanced A $\beta$ and tau pathology in transgenic mouse models of Alzheimer's disease. Acta Neuropathol. 2011; 122: 285-92.

52. Selkoe DJ, Hardy J. The amyloid hypothesis of Alzheimer's disease at 25 years. EMBO 
Mol Med. 2016; 8: 595-608.

885

53. Fakhoury M. Microglia and astrocytes in Alzheimer's disease: implications for therapy. Curr Neuropharmacol. 2017; 16: 508-18.

54. Holohan KN, Lahiri DK, Schneider BP, Foroud T, Saykin AJ. Functional microRNAs in Alzheimer's disease and cancer: Differential regulation of common mechanisms and pathways. Front. Genet. 2013; 3:323

890 55. Shaik MM, Tamargo IA, Abubakar MB, Kamal MA, Greig NH, Gan SH. The role of microRNAs in Alzheimer's disease and their therapeutic potentials. Genes (Basel). 2018; 9: 892 pii: E174. 56. Zuroff L, Daley D, Black KL, Koronyo-Hamaoui M. Clearance of cerebral A $\beta$ in Alzheimer's disease: reassessing the role of microglia and monocytes. Cell. Mol. Life Sci. 2017; 74: 2167-201. 57. Šerý O, Janoutová J, Ewerlingová L, Hálová A, Lochman J, Janout V, et al. CD36 gene polymorphism is associated with Alzheimer's disease. Biochimie. 2017; 135: 46-53. 58. Mishra A, Kim HJ, Shin AH, Thayer SA. Synapse loss induced by interleukin-1 $\beta$ requires pre-and post-synaptic mechanisms. J Neuroimmune Pharmacol. 2012; 7: 571-8.

900

901

902

903

904

905

906

907 


\section{Figure 1. SIRT1 expression is decreased in AD patients}

910 (A) Representative SIRT1 protein expression in control or AD precentral gyrus tissues ( $\mathrm{n}=6$ for

911

912

913

914

915

916

917

918

919

920

921

922

923

924

925

926

927

928

929

930

controls and AD patients, unpaired Student's $t$ test). (B) SIRT1 bands were analyzed by densitometry and normalized to actin. Relative levels of SIRT1 protein are shown from control $(n=6)$ or AD precentral gyrus $(n=6)$ tissues. $(C)$. Expression of SIRT1 in WT and 5XFAD mice with age. Messenger RNA expression (from NGS) of SIRT1 in 6 mo-old wild-type (WT) (n=4), 6 mo-old 5XFAD (n=3), 11 mo-old wild-type (WT) $(\mathrm{n}=3)$, and 11 mo-old 5XFAD mice $(\mathrm{n}=3)$. Comparative analyzes were performed for mice at the same ages. (D) Identification of SIRT1 expression in 5XFAD mice by age. Each age group's 5xFAD expression was normalized to WT.

Figure 2. miR-485-3p functionally binds to the 3'UTR of SIRT1 and suppresses its expression.

(A) SIRT1 and PGC-1 $\alpha$ protein expression in mouse primary cortical neurons transfected with miR-control, has-miR485-3p or miR485-3p ASO. (B) Relative levels of SIRT1 and PGC-1 $\alpha$ protein in miR-control, has-miR485-3p or miR485-3p ASO transfected mouse primary cortical neurons. (C) Schematic representation of the wild type (WT) or mutant form (MT) in SIRT1 3'-UTR showing the putative miR-485-3p target site. (D) Relative luciferase activity in HEK293T cells co-transfected with SIRT1 3'-UTR WT or MT reporter constructs and miRcontrol, miR-485-3p for $48 \mathrm{~h}$. At least three independent experiments were performed. (E) Relative binding of miR485-3p onto 3' UTR of SIRT1 harboring mutant seed region compared to WT 3' UTR of SIRT1. The data shown are representative of at least three independent 
experiments. All data are presented as the mean \pm SD.

Figure 3. miR485-3p ASO reduces A $\beta$ deposition and alters APP processing.

934

935

936

937

938

939

940

941

942

943

944

945

946

947

948

949

950

951

952

(A) Schedule of miR485-3p ASO ICV injections in 10 mo-old 5XFAD mice. (B) Representative images of immunohistochemical staining for $\mathrm{A} \beta(6 \mathrm{E} 10)$ in the cortex and hippocampal DG region from control $(n=5)$ and miR485-3p ASO $(n=5)$ injected 5XFAD mice. (C) Mean number of $A \beta$ plaques per $\mathrm{mm}^{2}$. (D) Immunoblot for insoluble $\mathrm{A} \beta$ fractions in control $(n=4)$ or miR485-3p ASO $(n=4)$ injected 10 mo-old 5XFAD mice. (E) Quantification of insoluble A $\beta$. Data are presented as the mean \pm SD. (F) APP, sAPP $\beta$, sAPP $\alpha, \beta-C T F s, B A C E 1$, Adam10 and SIRT1 protein expression in control $(n=3-4)$ or miR485-3p ASO $(n=3-5)$ injected 10 mo-old 5XFAD mice. (G) Relative levels of APP, sAPP $\beta$, sAPP $\alpha, \beta-C T F s$, BACE1, Adam10 and SIRT1 protein in control or miR485-3p ASO injected 10 mo-old 5XFAD mice.

Figure 4. miR485-3p ASO enhances phagocytosis of A $\beta$ by regulation of CD36 in vitro and in vivo

(A) Immunohistochemistry of Iba1 (microglia) and $\beta$-amyloid 1-16 (6E10, to detect A $\beta$ plaque) on coronal sections of control ( $\mathrm{n}=13$ images from five mice) or miR485-3p ASO ( $\mathrm{n}=11$ images from five mice) injected 5XFAD mice. The dot graph shows the mean number of $\mathrm{Iba1}^{+} \mathrm{A} \beta^{+}$ cells per $\mathrm{mm}^{2}$. (B) Immunohistochemistry performed on histological brain sections from control $(\mathrm{n}=6)$ or miR485-3p ASO $(\mathrm{n}=6)$ injected 5XFAD mice using anti-Iba1, anti-CD68 (phagosome) and anti- $\beta$-amyloid 1-16 (6E10). The dot graph shows the mean number of Iba $1^{+} \mathrm{A} \beta^{+} \mathrm{CD}^{+} 8^{+}$cells per $\mathrm{mm}^{2}$. (C) Control or miR485-3p ASO transfected BV2 microglia 
cells treated with fA $\beta(1-42)(1 \mu \mathrm{M})$. After $4 \mathrm{~h}$, supernatant was analyzed by using ELISA for

954 phagocytosis analysis. The data shown are representative of at least three independent 955 experiments. (D) Mouse primary microglia cells were transfected with control or miR485-3p 956 ASO and treated with $\mathrm{fA} \beta(1-42)(1 \mu \mathrm{M})$. After $4 \mathrm{~h}$, the cells were examined by 957 immunocytochemistry using Iba1 and 6E10 antibody. (E) Relative levels of CD36 protein 958 expression in control $(n=3)$ or miR485-3p ASO $(n=3)$ injected 10 mo-old 5XFAD mice. (F) 959 Cell surface expression of CD36 was analyzed by flow cytometry using Alexa488-conjugated 960 anti-CD36 antibody in control $(n=3)$, miR485-3p mimic or miR485-3p ASO $(n=3)$ transfected 961 primary mixed glial cells. Data from at least three independent experiments are presented. $(\mathrm{G})$ Relative luciferase activity in HEK293T cells co-transfected with CD36 3'-UTR WT or MT reporter constructs and miR-control, miR-485-3p for 48 h. At least three independent experiments were performed. $(\mathrm{H})$ Relative binding of miR485-3p onto 3' UTR of CD36 harboring mutant seed sequences compared to WT 3' UTR of CD36. (I) fA $\beta(1-42)(1 \mu \mathrm{M})$ were treated in control or miR485-3p ASO transfected BV2 microglia cells with IgG or CD36blocking antibody. After $4 \mathrm{~h}$, supernatant was analyzed by using ELISA for phagocytosis analysis. The graphs show the results from at least three independent experiments. Data are presented as the mean $\pm \mathrm{SD}$.

Figure 5. miR485-3p ASO reduces neuroinflammation in glial cells.

972 (A) Control or miR485-3p ASO transfected in primary mixed glial cells treated with fA $\beta$ (1973 42) $(1 \mu \mathrm{M})$. After 3 , and $6 \mathrm{~h}$, SIRT1, NF- $\kappa \mathrm{B}$ (p65), TNF- $\alpha$ and IL-1 $\beta$ protein was determined by western blot analysis. Data are representative of at least three independent experiments. (B) Relative levels of SIRT1, NF-кB (p65), TNF- $\alpha$ and IL-1 $\beta$ protein in control or miR485-3p 976 ASO transfected primary mixed glial cells. (C) Immunoblot detection of Iba1, NF-кB (p65), 
TNF- $\alpha$ and IL-1 $\beta$ protein in control $(n=3)$ or miR485-3p ASO $(n=3)$ injected 10 mo-old 5XFAD mice. (D) Relative levels of Iba1, NF- $\kappa \mathrm{B}$ (p65), TNF- $\alpha$ and IL-1 $\beta$ protein. (E) Immunohistochemical staining for Iba1 and TNF- $\alpha$ in the control ( $\mathrm{n}=11$ images from five mice) or miR485-3p ASO ( $\mathrm{n}=11$ images from five mice) injected 5XFAD mice. (F) Mean number of Iba1 and TNF- $\alpha$-stained cells per $\mathrm{mm}^{2}$. (G) Immunohistochemical staining for Iba1 and IL-1 $\beta$ in the control ( $\mathrm{n}=11$ images from five mice) or miR485-3p ASO ( $\mathrm{n}=11$ images from five mice) injected 5XFAD mice. $(\mathrm{H})$ Mean number of Iba1 and IL-1 $\beta$-stained cells per $\mathrm{mm}^{2}$. All data are presented as the mean $\pm \mathrm{SD}$.

985

Figure 6. miR485-3p ASO administration ameliorates neuronal loss and improves 987 cognitive decline in 5XFAD.

988

(A) NeuN protein expression in control $(n=3)$ or miR485-3p ASO $(n=5)$ injected 10 mo-old 5XFAD mice. (B) Relative levels of NeuN protein in control or miR485-3p ASO injected 10 mo-old 5XFAD mice. (C) Immunohistochemical staining for NeuN and cleaved caspase-3 in coronal brain sections from control $(\mathrm{n}=4)$ or miR485-3p ASO $(\mathrm{n}=5)$ injected 10 mo-old 5XFAD mice. (D) Mean number of NeuN and cleaved caspase-3-stained cells per $\mathrm{mm}^{2}$. (E) Immunoblot detection of PSD-95 protein in control $(n=3)$ or miR485-3p ASO $(n=5)$ injected 10 mo-old 5XFAD mice. (F) Relative levels of PSD-95 protein. (G-H) Behavior tests in control $(\mathrm{n}=5-7)$ or miR485-3p ASO $(\mathrm{n}=5-7)$ injected 10 mo-old 5XFAD mice. Y-maze $(\mathrm{G})$ and passive avoidance test $(\mathrm{H})$ control or miR485-3p ASO injected 10 mo-old 5XFAD mice. Average alternation (\%) for control or miR485-3p injected 5XFAD mice and total entry number into each arm on Y-maze. Average step through latency and time in dark compartment in seconds for control or miR485-3p injected 5XFAD mice on passive avoidance test. All data are presented as the mean $\pm \mathrm{SD}$. 

miR485-3p ASO in 5XFAD increases SIRT1 expression in neurons. SIRT1 in turn reduces amyloid beta production through regulation of amyloid production enzymes. Also, miR485-3p ASO enhances CD36 expression and phagocytosis of $A \beta$ plaque in glial cells. At the same time, 1005 miR485-3p ASO induced SIRT1 expression reduces neuroinflammation and neuronal damage.

1006

1007

1008

1009

1010

1011

1012

1013

1014

1015

1016

1017

1018

1019

1020 
Additional file 1: Table S1. Characteristics of human brain tissue donor. Related to Fig.

1. Patient information for control or AD brain precentral gyrus tissues used in this study

1024

1025

Additional file 2: Figure S1. miRNA485-3p and SIRT1 signature overlap in AD patient

brain. (A) High expression pattern of hsa-miR-485-3p among Weinberg et al. Hsa-miR-485$3 p$ is located at the 19th of 31 up-expression miRNAs. (B). Dots show hsa-miR-485-3p or hasmiR-485-5p quantified values normalized to those of $16 \mathrm{~S}$ RNA (control $n=6$ or AD patient $n=6$, unpaired Student's $t$ test) (C) Venn diagram represents that a total of 202 miRNAs to bind 3'UTR of SIRT1 were predicted through "miRDB". Hsa-miR-485-3p was only miRNA that shared between up-expression miRNAs (in this additional file: Figure S1A) and SIRT1 target miRNAs. (D) Graphs show the relative levels of mouse miR485-3p expression in control or miR485-3p ASO transfected 14DIV primary cortical neuron.

1034

Additional file 3: Figure S2. Protein interaction networks of SIRT1. (A) Venn-diagram analysis across hsa-miR-485-3p target genes, inflammation related genes, amyloid beta degradation related genes and Alzheimer related genes. Target gene prediction results of hsamiR-485-3p were carried out through "miRDB". The other three groups of genes were examined by entering keywords into "Genecard" (https://www.genecards.org/). (B) The input genes were used the 265 common genes of hsa-miR-485-3p target genes and Alzheimer-related genes as mentioned previous additional file: Figure S1. The categories of networks used in this analysis were the "physical interactions" and "pathway" of human. See Materials and Methods for a description of the options and gene pools. 
Additional file 4: Figure S3. Efficacy evaluation of miR485-3p ASO using intraventricular

injection. Reduced miR485-3p expression level in the frontal cortex of 5XFAD mice following

1047

1048

1049

1050

1051

1052

1053

1054

1055

1056

1057

1058

1059

1060

1061

1062

1063

1064

1065

1066

intraventricular injection of control or miR485-3p ASO. Graphs show the relative levels of mouse miR485-3p expression in control $(n=3)$ or miR485-3p ASO $(n=5)$ injected 5XFAD mice.

Additional file 5: Figure S4. miR485-3p ASO reduces A $\beta$ burden in 5XFAD. Representative images of ThS staining to Ab plaque in hippocampus and cortex of control $(n=7$ images from three mice) or miR485-3p ASO ( $n=7$ images from three mice) administrated mice.

The data are presented as the mean \pm SD. Statistics were performed with unpaired $t$-test.

Additional file 6: Figure S5. miR485-3p increases capacity of $A \beta$ uptake by CD36 expression in vitro and vivo. (A) Immunohistochemistry was performed on histological brain sections from the control or miR485-3p ASO 5XFAD mice using anti-GFAP and anti- $\beta$ amyloid 1-16 (6E10). (B) Fibrilliar form of $A \beta$ analyzed by western blot using anti- $\beta$-amyloid 1-16 (6E10). (C) Control or miR485-3p ASO transfected in primary glial cell and treated with fA $\beta(1 \mu \mathrm{M})$. After $4 \mathrm{~h}$, the cells were examined by immunocytochemistry using a GFAP and 6E10 antibody. (D) Control or miR485-3p ASO transfected BV2 microglia cells and primary glial cells treated with $\mathrm{fA} \beta(1-42)(1 \mu \mathrm{M})$. After $4 \mathrm{~h}, \mathrm{~A} \beta$ insoluble fraction was analyzed by western blot for analysis of uptake capacity. The data shown are representative of at least three independent experiments. (E) Antibodies against Iba1 and CD36 were used to perform immunohistochemistry on coronal sections of the control or miR485-3p ASO injected 5XFAD mice. 
1067 Additional file 7: Figure S6. Delivery of miR485-3p ASO reduces neuroinflammation in 1068 glial cells. (A) Control or miR485-3p ASO transfected in primary glial cell with fA $\beta(1 \mu \mathrm{M})$. 1069 After $6 \mathrm{~h}$, the representative of TNF- $\alpha$ and IL-1 $\beta$ transcript level was examined by real time 1070 PCR. The data shown are representative of at least three independent experiments. (B) 1071 Immunoblot detection of GFAP protein in control $(n=3)$ or miR485-3p ASO $(n=3)$ injected 1072 5XFAD mice. (C-D) Antibodies against GFAP, TNF- $\alpha$, IL-1 $\beta$ were used to perform 1073 immunohistochemistry on coronal sections of control or miR485-3p ASO injected 5XFAD 1074 mice. 
Figures

\section{Figure 1}

A

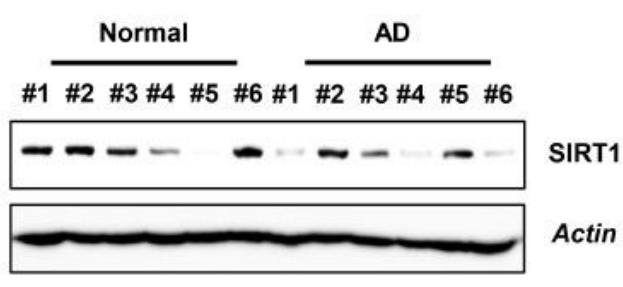

C

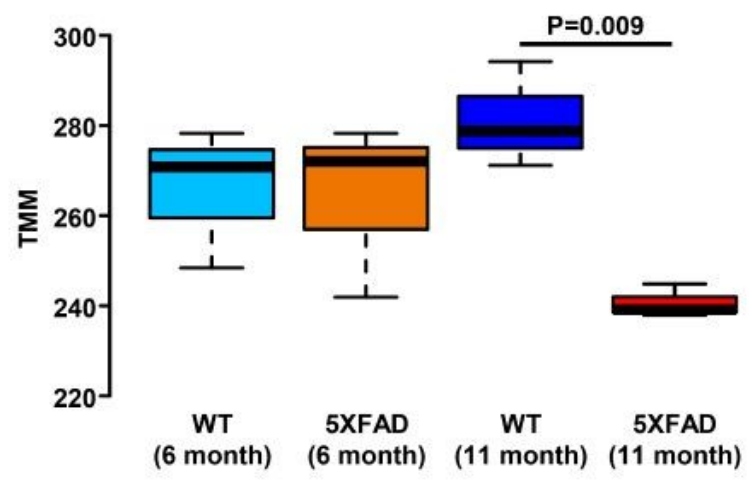

B

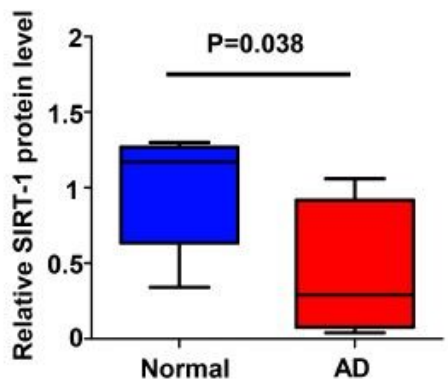

D

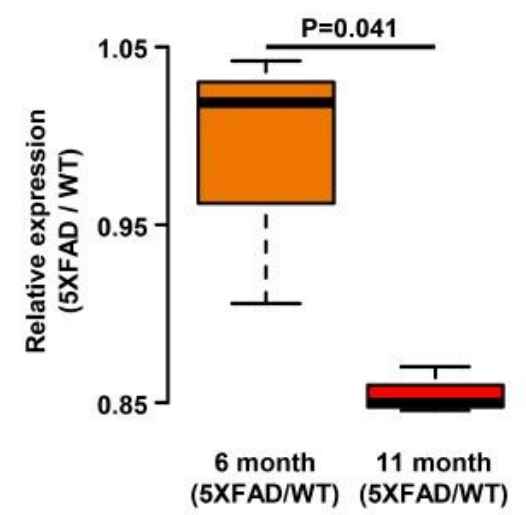

\section{Figure 1}

SIRT1 expression is decreased in AD patients (A) Representative SIRT1 protein expression in control or AD precentral gyrus tissues ( $n=6$ for controls and AD patients, unpaired Student's t test). (B) SIRT1 bands were analyzed by densitometry and normalized to actin. Relative levels of SIRT1 protein are shown from control $(n=6)$ or AD precentral gyrus $(n=6)$ tissues. (C). Expression of SIRT1 in WT and 5XFAD mice with age. Messenger RNA expression (from NGS) of SIRT1 in 6 mo-old wild-type (WT) ( $n=4), 6$ mo-old 5XFAD ( $n=3), 11$ mo-old wild-type (WT) ( $n=3)$, and 11 mo-old 5XFAD mice ( $n=3)$. Comparative analyzes were performed for mice at the same ages. (D) Identification of SIRT1 expression in 5XFAD mice by age. Each age group's 5xFAD expression was normalized to WT. 
Figure 2

A

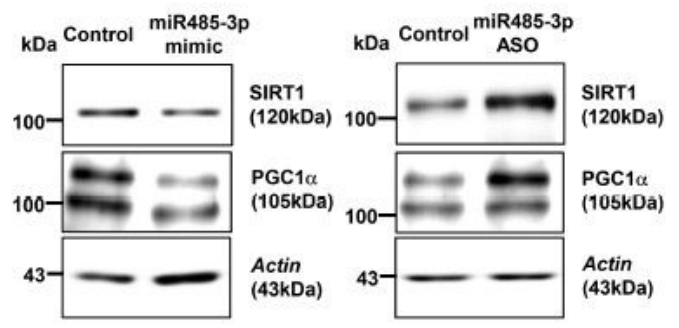

C

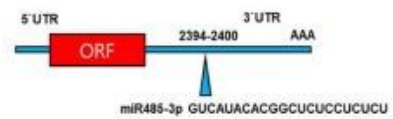

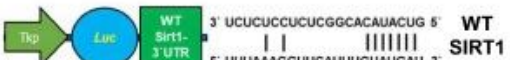

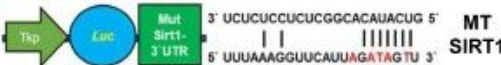

B
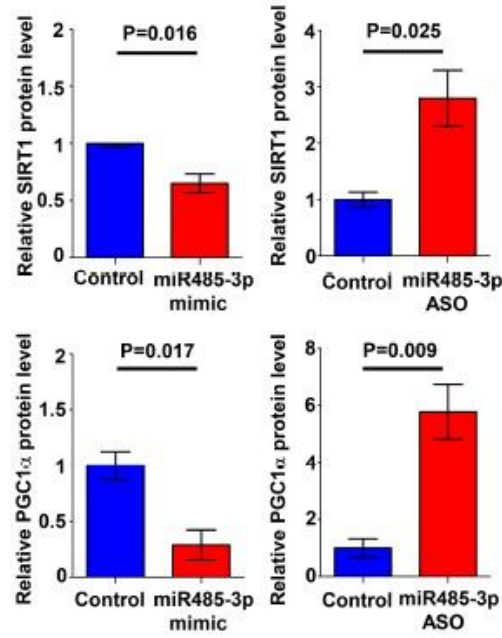

E
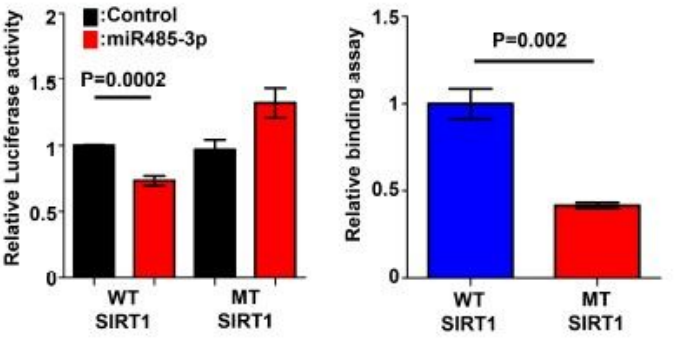

Figure 2

miR-485-3p functionally binds to the 3

UTRofSIRT1 and $\square$ pressesitsexpression. (A)SIRT1 and PGC - 1 prote $\square$ expression $\square$ mouseprimaryc or tical $\neq$ uronstranectedwithmiR - control, has - miR48 5 -UTR showing the putative miR-485-3p target site. (D) Relative luciferase activity in HEK293T cells co-transfected with SIRT1 3'-UTR WT or MT reporter constructs and miR928 control, miR-485-3p for 48 h. At least three independent experiments were performed. (E) Relative binding of miR485-3p onto 3' UTR of SIRT1 harboring mutant seed region compared 930 to WT 3' UTR of SIRT1. The data shown are representative of at least three independent experiments. All data are presented 931 as the mean \pm SD. 
Figure 3

A

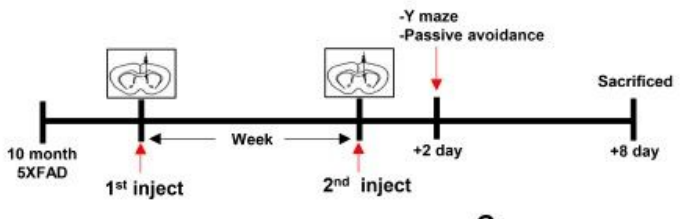

B

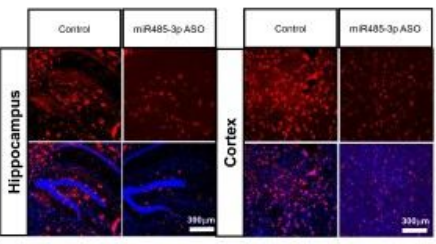

D

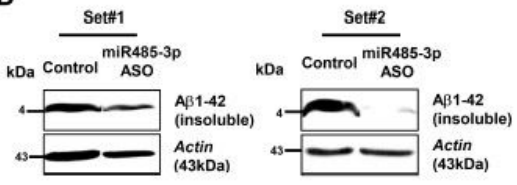

$\mathbf{F}$

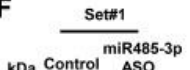

kDa Control ${ }_{\text {ASO }}^{\text {miR485-3p }}$

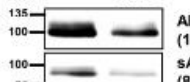

SAPP $\beta$
$(85 \mathrm{kDa})$

SAPPa

B-CTFs

(12kDa)

(70kDa)
Adam10

(84kDa)

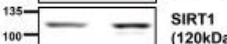

(120kDa)

(105kDa)

Actin
(43kDa)
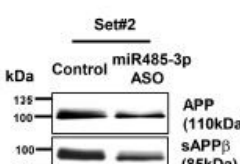

(85kDa)

SAPP $\alpha$
(95kDa)

B-CTFs

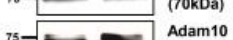

(84kDa)

(84kDa)
SIRT1

(120kDa)

PGĆ1a

(105kDa)

Actin
(43kDa)
BACE1
C

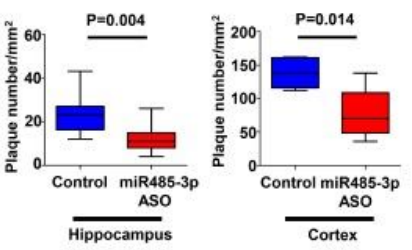

E

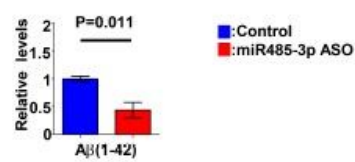

G
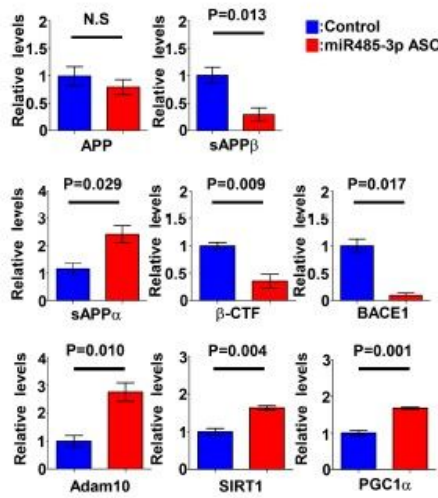

Figure 3

miR485-3p ASO reduces A deposition and alters APP processing. (A) Schedule of miR485-3p ASO ICV injections in 10 mo-old 5XFAD mice. (B) Representative images of immunohistochemical staining for $A \beta(6 E 10)$ in the cortex and hippocampal DG region from control $(n=5)$ and miR485-3p ASO $(n=5)$ injected 5XFAD mice. (C) Mean number of A plaques per mm2. (D) Immunoblot for insoluble A fractions in control $(n=4)$ or miR485-3p ASO ( $n=4)$ injected 10 mo-old 5XFAD mice. (E) Quantification of insoluble AData are presented as the mean \pm SD. (F) APP, sAPP $\beta$, sAPP, $\beta$-CTFs, BACE1, Adam10 and SIRT1 protein expression in control $(n=3-4)$ or miR485-3p ASO ( $n=3-5)$ injected 10 mo-old 5XFAD mice. (G) Relative levels of APP, sAPP 3, sAPP, $\beta$-CTFs, BACE1, Adam10 and SIRT1 protein in control or miR485-3p ASO injected 10 mo-old 5XFAD mice. 


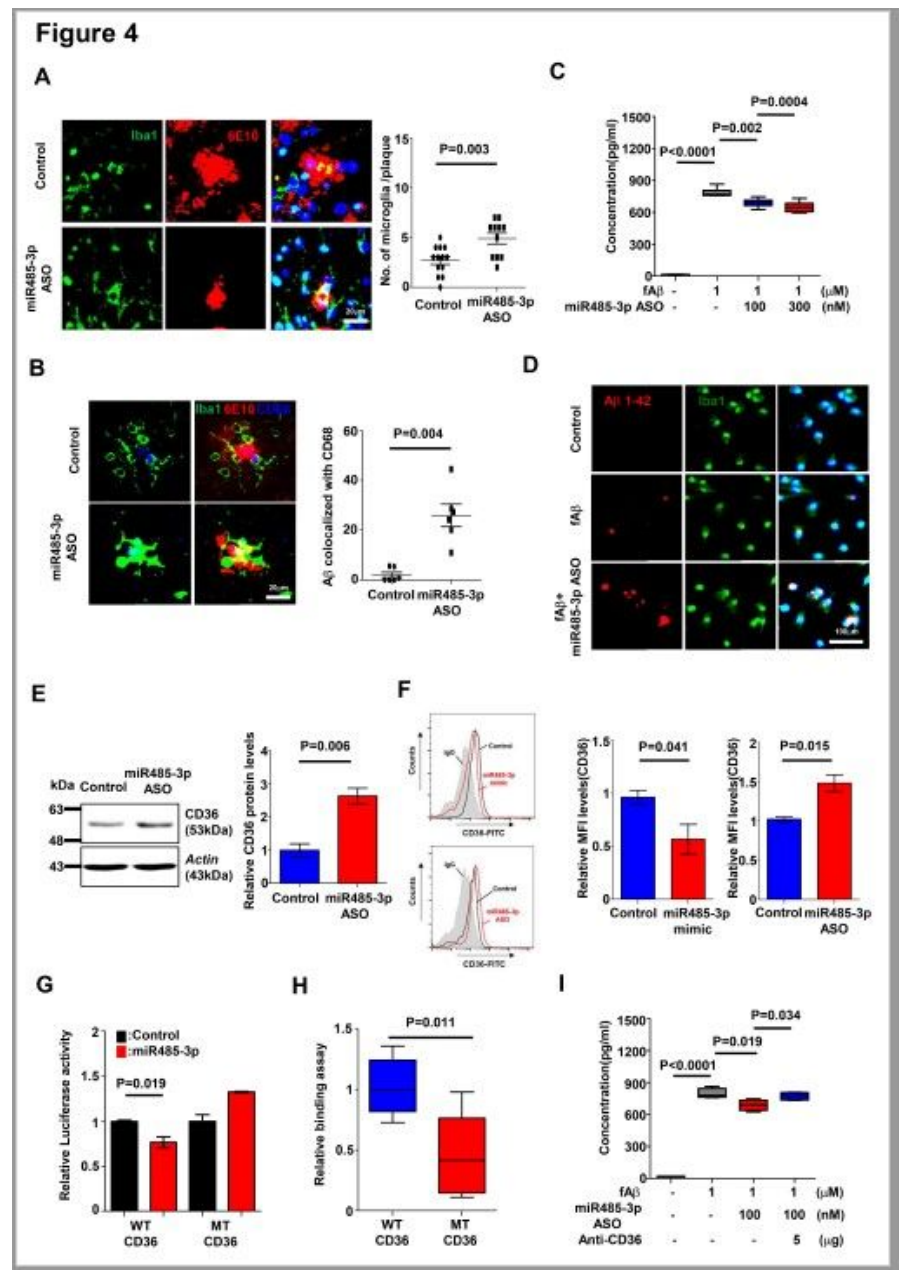

Figure 4

miR485-3p ASO enhances phagocytosis of A by regulation of CD36 in vitro and in vivo (A) Immunohistochemistry of Iba1 (microglia) and -amyloid 1-16 (6E10, to detect A plaque) on coronal sections of control ( $n=13$ images from five mice) or miR485-3p ASO ( $n=11$ images from five mice) injected 5XFAD mice. The dot graph shows the mean number of Iba1+A+ cells per mm2. (B) Immunohistochemistry performed on histological brain sections from control ( $\mathrm{n}=6$ ) or miR485-3p ASO ( $n=6)$ injected 5XFAD mice using anti-lba1, anti-CD68 (phagosome) and anti-amyloid 1-16 (6E10). The dot graph shows the mean number of lba1+A+ CD68+ cells per mm2. (C) Control or miR485-3p ASO transfected BV2 microglia cells treated with fA(1-42)(1M). After 4 h, supernatant was analyzed 953 by using ELISA for phagocytosis analysis. The data shown are representative of at least three independent experiments. (D) Mouse primary microglia cells were transfected with control or miR485-3p ASO and treated with $\mathrm{fA}(1-42)(1 \mathrm{M})$. After $4 \mathrm{~h}$, the cells were examined by immunocytochemistry using Iba1 and 6E10 antibody. (E) Relative levels of CD36 protein expression in control $(n=3)$ or miR485-3p ASO ( $n=3$ ) injected 10 mo-old 5XFAD mice. (F) Cell surface expression of CD36 was analyzed by flow cytometry using Alexa488-conjugated anti-CD36 antibody in control ( $n=3)$, miR485-3p mimic or miR485-3p ASO $(n=3)$ transfected primary mixed glial cells. Data from at least three independent experiments are presented. (G) Relative luciferase activity in HEK293T cells co-transfected with CD36 3'-UTR WT or MT reporter constructs and miR-control, miR-485-3p for $48 \mathrm{~h}$. At least three independent experiments were performed. $(\mathrm{H})$ Relative binding of miR485-3p onto 3' UTR of CD36 harboring mutant seed sequences compared to WT 3' UTR of CD36. (I) fA(1-42)(1M) were treated in control or miR485-3p ASO transfected BV2 microglia cells with IgG or CD36- blocking antibody. After 4 h, supernatant was analyzed by using ELISA for phagocytosis analysis. The graphs show the results from at least three independent experiments. Data are presented as the mean \pm SD. 


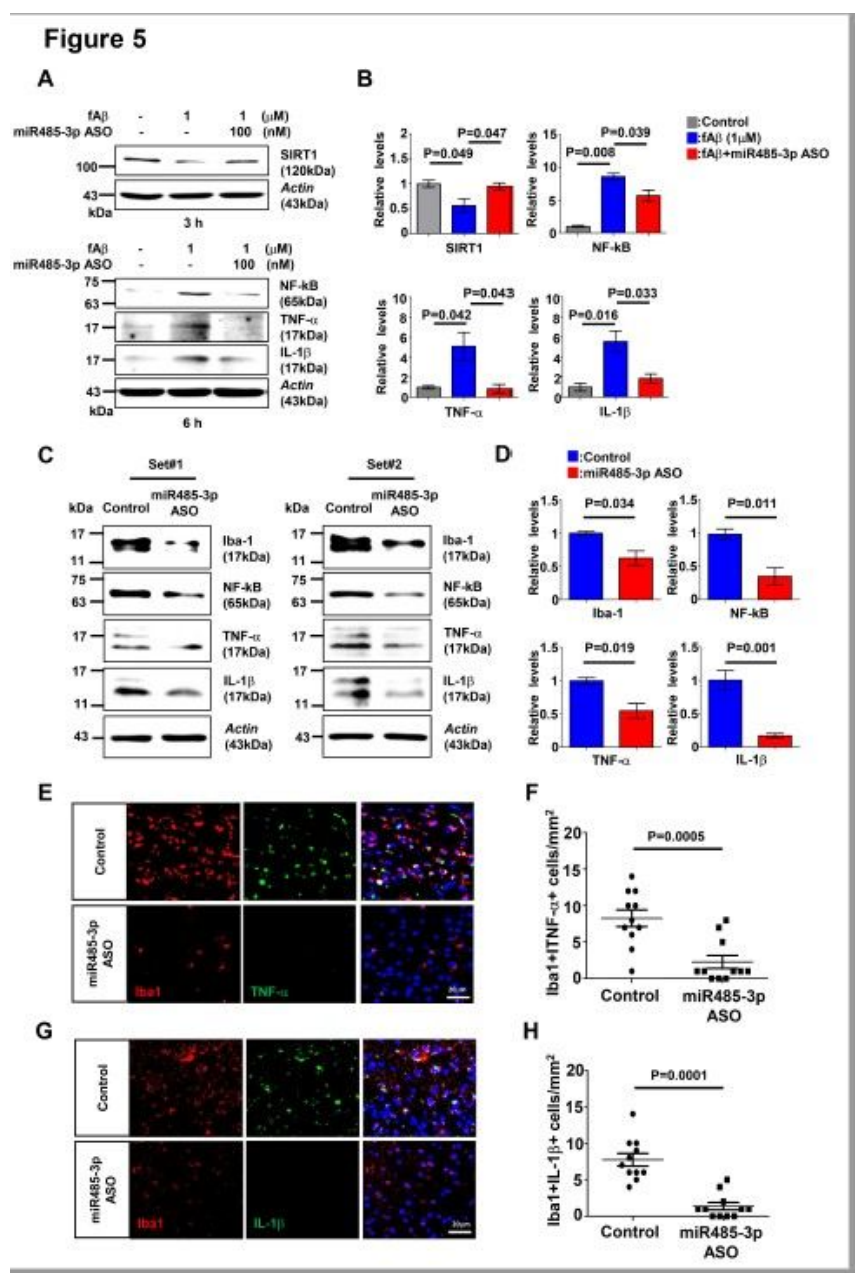

\section{Figure 5}

miR485-3p ASO reduces neuroinflammation in glial cells. (A) Control or miR485-3p ASO transfected in primary mixed glial cells treated with $\mathrm{fA}(1-42)(1 \mathrm{M})$. After 3, and 6 h, SIRT1, NF-B (p65), TNF- and IL-1 protein was determined by western blot analysis. Data are representative of at least three independent experiments. (B) Relative levels of SIRT1, NF-B (p65), TNF- and IL-1 protein in control or miR485-3p ASO transfected primary mixed glial cells. (C) Immunoblot detection of Iba1, NF-B (p65), TNF- and IL-1 protein in control $(n=3)$ or miR485-3p ASO ( $n=3) 977$ injected 10 mo-old 5XFAD mice. (D) Relative levels of Iba1, NF-B (p65), TNF- and IL-1 protein. (E) Immunohistochemical staining for Iba1 and TNF- in the control ( $n=11$ images from five mice) or miR485-3p ASO ( $n=11$ images from five mice) injected 5XFAD mice. (F) Mean number of Iba1 and TNF--stained cells per mm2. (G) Immunohistochemical staining for Iba1 and IL-1 in the control ( $n=11$ images from five mice) or miR485-3p ASO ( $n=11$ images from five mice) injected 5XFAD mice. (H) Mean number of Iba1 and IL-1-stained cells per $\mathrm{mm} 2$. All data are presented as the mean $\pm \mathrm{SD}$. 
A

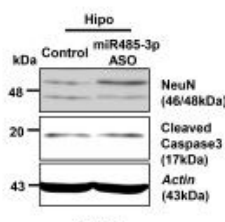

$\frac{\text { Cortex }}{\text { Control mir4 } 455-3 p}$
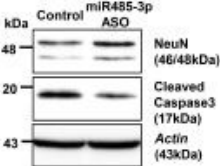

B
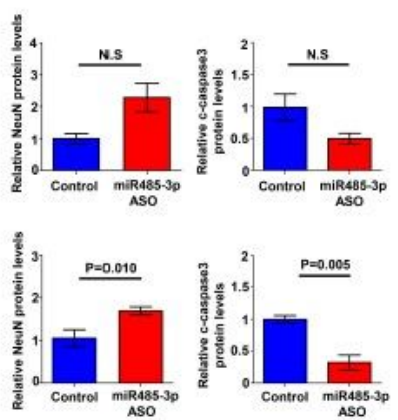

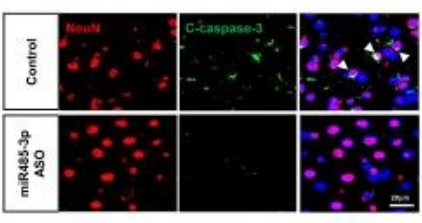

E

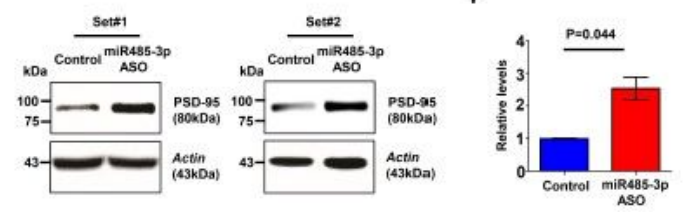

F

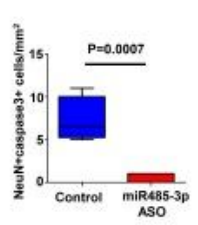

H

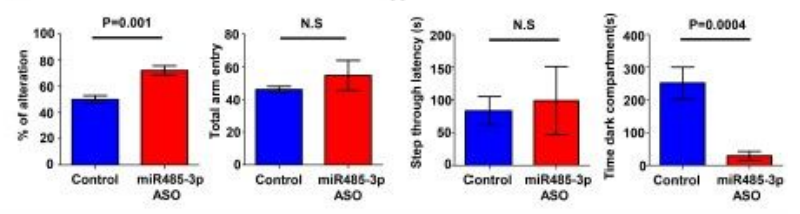

Figure 6

miR485-3p ASO administration ameliorates neuronal loss and improves cognitive decline in 5XFAD. (A) NeuN protein expression in control ( $n=3$ ) or miR485-3p ASO $(n=5)$ injected 10 mo-old 5XFAD mice. (B) Relative levels of NeuN protein in control or miR485-3p ASO injected 10 mo-old 5XFAD mice. (C) Immunohistochemical staining for NeuN and cleaved caspase-3 in coronal brain sections from control $(n=4)$ or miR485-3p ASO ( $n=5)$ injected 10 mo-old 5XFAD 992 mice. (D) Mean number of NeuN and cleaved caspase-3-stained cells per mm2. (E) Immunoblot detection of PSD-95 protein in control ( $n=3$ ) or miR485-3p ASO ( $n=5)$ injected 10 mo-old 5XFAD mice. (F) Relative levels of PSD-95 protein. (G-H) Behavior tests in control ( $n=5-7)$ or miR485-3p ASO ( $n=5-7)$ injected 10 mo-old 5XFAD mice. Y-maze (G) and passive avoidance test $(\mathrm{H})$ control or miR485-3p ASO injected 10 mo-old 5XFAD mice. Average alternation (\%) for control or miR485-3p injected 5XFAD mice and total entry number into each arm on Y-maze. Average step through latency and time in dark compartment in seconds for control or miR485-3p injected 5XFAD mice on passive avoidance test. All data are presented as the mean \pm SD. 
Figure 7

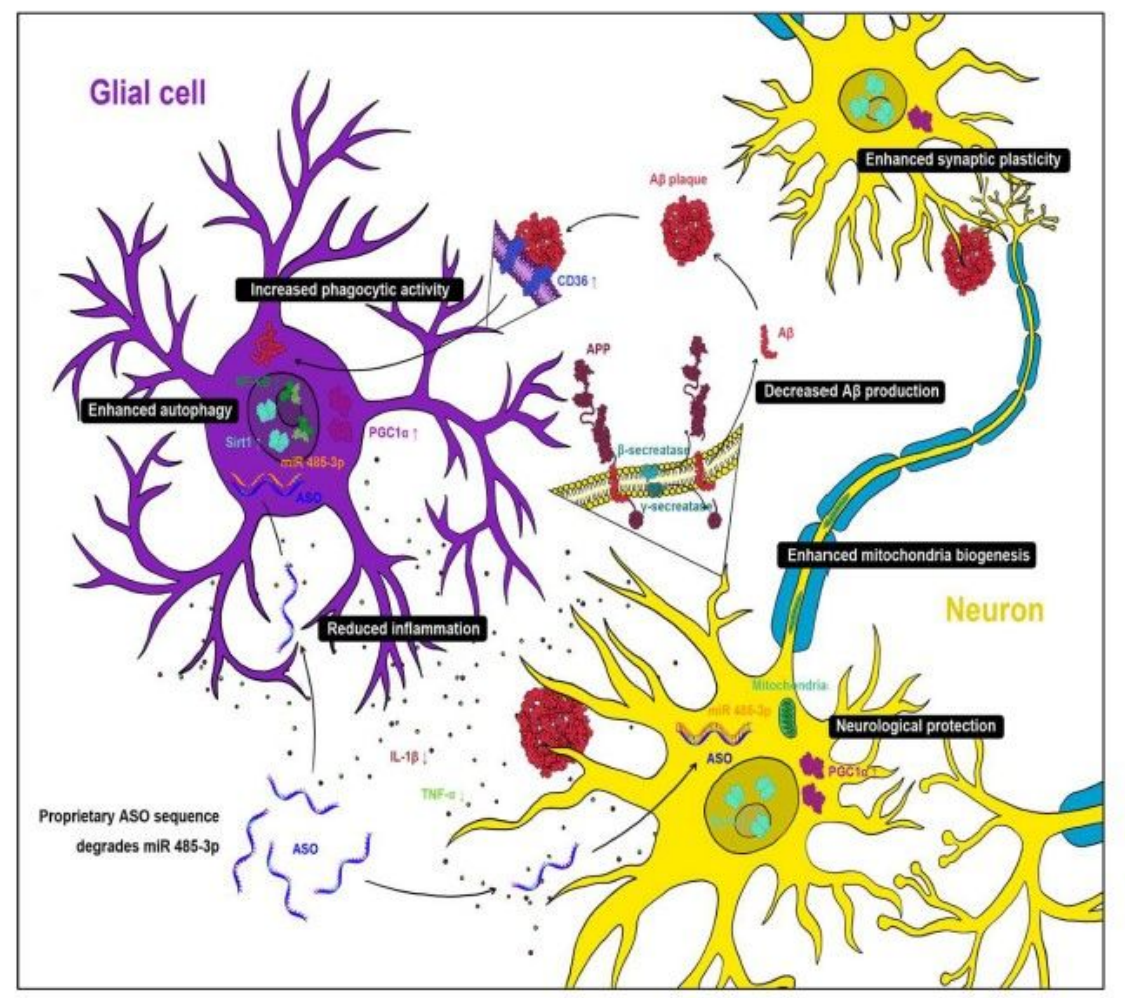

Figure 7

Schematic depicting possible miR485-3p ASO associated 1001 events in 5XFAD. miR485-3p ASO in 5XFAD increases SIRT1 expression in neurons. SIRT1 in turn reduces amyloid beta production through regulation of amyloid production enzymes. Also, miR485-3p ASO enhances CD36 expression and phagocytosis of A plaque in glial cells. At the same time, miR485-3p ASO induced SIRT1 expression reduces neuroinflammation and neuronal damage.

\section{Supplementary Files}

This is a list of supplementary files associated with this preprint. Click to download.

- Figures3.pdf

- Figures4.pdf

- Figures1.pdf

- tables1.pdf

- Figures6.pdf

- Figures5.pdf

- Figures2.pdf

- Figures3.pdf 